\title{
Mechanical Cues: Bidirectional Reciprocity in the Extracellular Matrix Drives Mechano-Signalling in Articular Cartilage
}

\author{
Sophie Jane Gilbert, Cleo Selina Bonnet and Emma Jane Blain*
}

Citation: Gilbert, S.J.; Bonnet, C.S.; Blain, E.J. Mechanical Cues: Bidirectional Reciprocity in the Extracellular Matrix Drives Mechano-Signalling in Articular Cartilage. Int. J. Mol. Sci. 2021, 22, 13595. https://doi.org/10.3390/ ijms222413595

Academic Editor: James Melrose

Received: 18 November 2021 Accepted: 15 December 2021 Published: 18 December 2021

Publisher's Note: MDPI stays neutral with regard to jurisdictional claims in published maps and institutional affiliations.

Copyright: (c) 2021 by the authors. Licensee MDPI, Basel, Switzerland. This article is an open access article distributed under the terms and conditions of the Creative Commons Attribution (CC BY) license (https:/ / creativecommons.org/licenses/by/ $4.0 /)$.
Biomechanics and Bioengineering Centre Versus Arthritis, School of Biosciences, Cardiff University, Cardiff CF10 3AX, UK; gilbertsj1@cardiff.ac.uk (S.J.G.); bonnetcs@cardiff.ac.uk (C.S.B.)

* Correspondence: blain@cardiff.ac.uk

Abstract: The composition and organisation of the extracellular matrix (ECM), particularly the pericellular matrix (PCM), in articular cartilage is critical to its biomechanical functionality; the presence of proteoglycans such as aggrecan, entrapped within a type II collagen fibrillar network, confers mechanical resilience underweight-bearing. Furthermore, components of the PCM including type VI collagen, perlecan, small leucine-rich proteoglycans-decorin and biglycan - and fibronectin facilitate the transduction of both biomechanical and biochemical signals to the residing chondrocytes, thereby regulating the process of mechanotransduction in cartilage. In this review, we summarise the literature reporting on the bidirectional reciprocity of the ECM in chondrocyte mechano-signalling and articular cartilage homeostasis. Specifically, we discuss studies that have characterised the response of articular cartilage to mechanical perturbations in the local tissue environment and how the magnitude or type of loading applied elicits cellular behaviours to effect change. In vivo, including transgenic approaches, and in vitro studies have illustrated how physiological loading maintains a homeostatic balance of anabolic and catabolic activities, involving the direct engagement of many PCM molecules in orchestrating this slow but consistent turnover of the cartilage matrix. Furthermore, we document studies characterising how abnormal, non-physiological loading including excessive loading or joint trauma negatively impacts matrix molecule biosynthesis and/or organisation, affecting PCM mechanical properties and reducing the tissue's ability to withstand load. We present compelling evidence showing that reciprocal engagement of the cells with this altered ECM environment can thus impact tissue homeostasis and, if sustained, can result in cartilage degradation and onset of osteoarthritis pathology. Enhanced dysregulation of PCM/ECM turnover is partially driven by mechanically mediated proteolytic degradation of cartilage ECM components. This generates bioactive breakdown fragments such as fibronectin, biglycan and lumican fragments, which can subsequently activate or inhibit additional signalling pathways including those involved in inflammation. Finally, we discuss how bidirectionality within the ECM is critically important in enabling the chondrocytes to synthesise and release PCM/ECM molecules, growth factors, pro-inflammatory cytokines and proteolytic enzymes, under a specified load, to influence PCM/ECM composition and mechanical properties in cartilage health and disease.

Keywords: articular cartilage; mechanobiology; extracellular/pericellular matrix; homeostatic balance; osteoarthritis

\section{Introduction}

Articular cartilage, located at the ends of diarthrodial joints, has a unique biochemical composition that confers its functional properties, the principal function being the dissipation of mechanical forces evenly across the joint surface. The composition of the extracellular matrix (ECM) in articular cartilage is critical to its function, and it is well known that the presence of proteoglycans embedded within a collagen fibrillar network provides biomechanical resilience. Furthermore, the spatial distribution of these ECM molecules within the tissue also facilitates its capability to withstand mechanical loads, as well as perceive biomechanical 
signals transducing them to the chondrocytes (only cell type in cartilage) to effect cellular responses. This bidirectionality within the ECM is critically important in enabling the chondrocytes to sense load application, including altered loading patterns, but also to influence ECM composition as a consequence of mechanical cues (Figure 1).

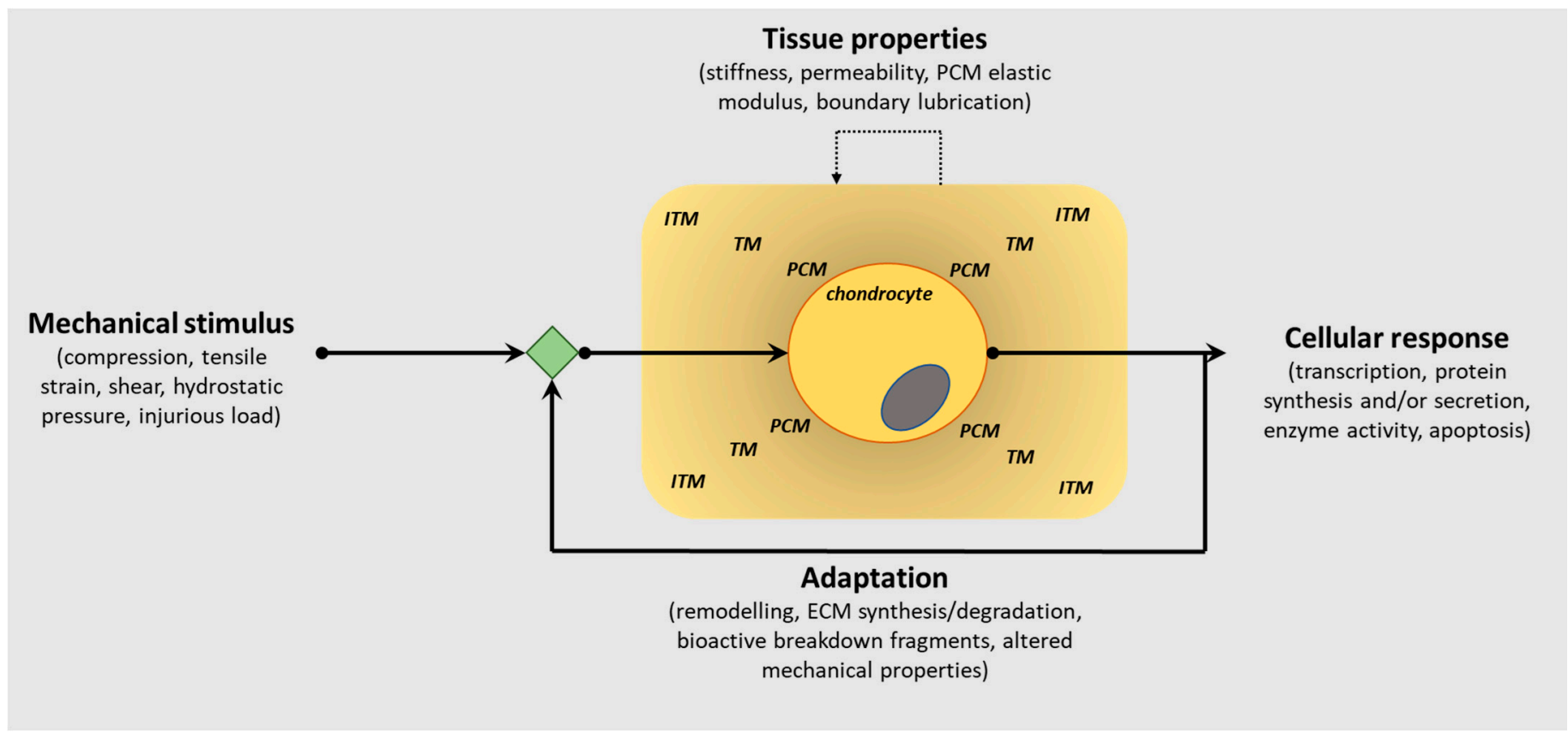

Figure 1. Schematic representation of the bidirectional reciprocity of the pericellular/extracellular matrix (ECM) in chondrocyte mechano-signalling and articular cartilage homeostasis. This bidirectionality within the extracellular matrix (ECM) is critically important in enabling the chondrocytes to sense load application, including altered loading patterns, but also to influence PCM/ECM composition as a consequence of mechanical cues to regulate the structural, biomechanical and functional characteristics of articular cartilage in tissue health and pathology. (PCM, pericellular matrix; TM, territorial matrix; ITM, interterritorial matrix).

Articular cartilage is unique in being avascular, aneural and alymphatic and is largely comprised of a dense ECM interspersed with chondrocytes, which account for only 5-10\% of tissue volume [1]. It is a multiple layer structure consisting of a superficial zone (SZ), middle zone, deep zone, tidemark and calcified layer (Figure 2A); the highly organised distribution of the ECM constituents within these layers and their interactions provides a porous and permeable tissue that facilitates the long-term load-bearing capabilities of the joint [2-4]. The principal component of the cartilage ECM is water (60-85\% by wet weight), whereas the remaining mass comprises a crosslinked network of type II collagen (15-22\% by wet weight), proteoglycans (4-7\% by wet weight) and smaller amounts of other collagen types, e.g., types VI, IX, X and XI, and non-collagenous proteins, e.g., fibronectin $(F N)$ and tenascin $[5,6]$. Produced in large amounts by synoviocytes and SZ chondrocytes, lubricin, encoded by the proteoglycan 4 (Prg4) gene, colocalises with cartilage oligomeric protein (COMP) and binds FN and type II collagen [7]. It contributes to the highly lubricated cartilage surface [8] and is critical for SZ integrity since mice lacking Prg4 exhibit a loss of cartilage structure, change in stiffness and frictional properties [9] and develop cartilage wear as they age $[10,11]$. Mechanistically this may occur via the nuclear factor- $\mathrm{B}-\mathrm{matrix}$ metalloproteinase 9-transforming growth factor beta (NFkB-MMP9-TGF $\beta$ ) axis since lubricin is increased by TGF $\beta$ and lubricin suppresses SZ MMP9 expression preventing chondrocyte differentiation $[7,12]$. Recently, $\beta$-catenin signalling has also been linked to lubricin's role in maintaining cartilage surface integrity since deletion of $\beta$-catenin in Prg4-expressing SZ cells leads to failure of the SZ and enhanced progression of osteoarthritis (OA) [13]. 
(A)

(B)

Increasing load

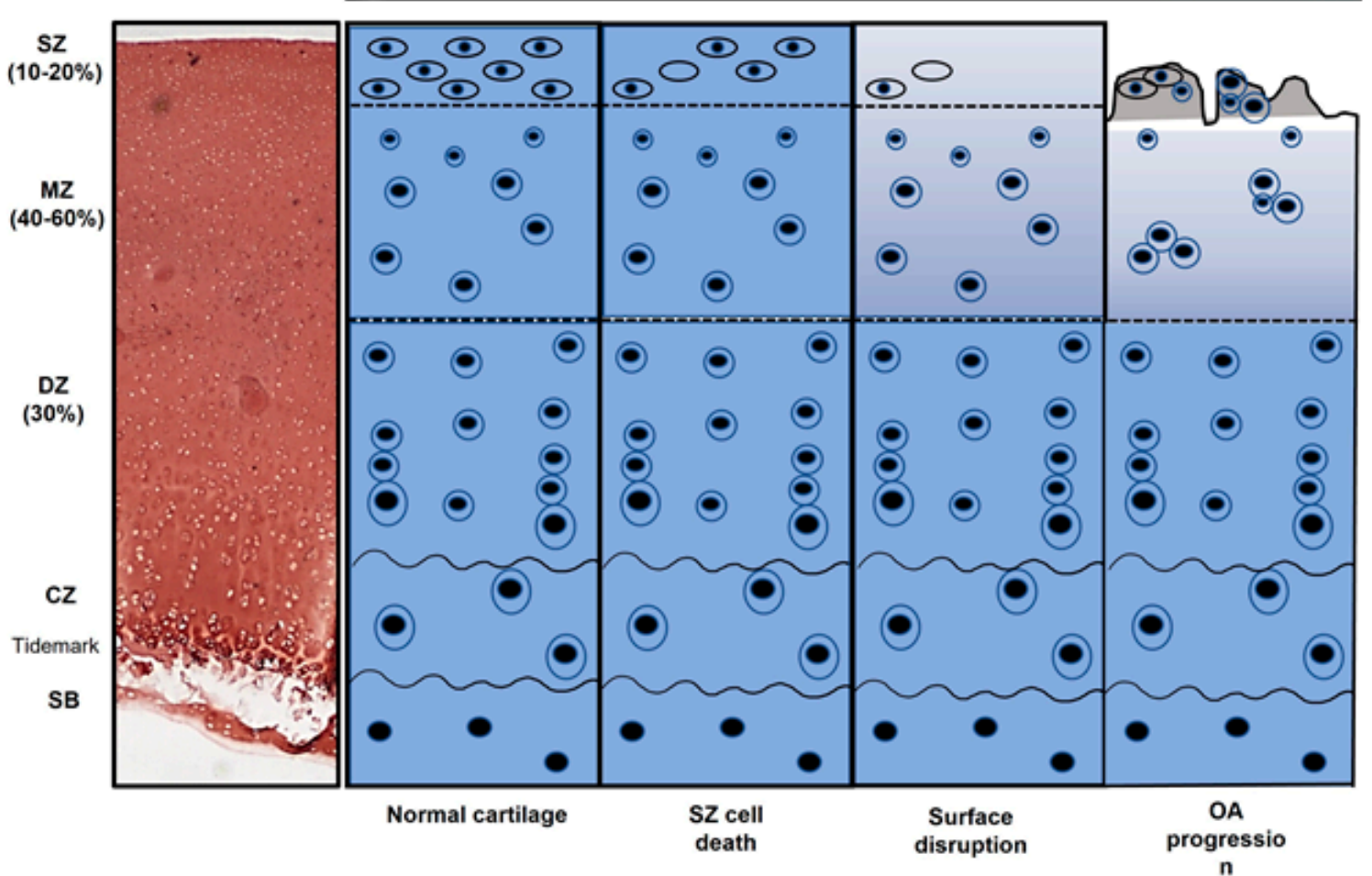

(C)

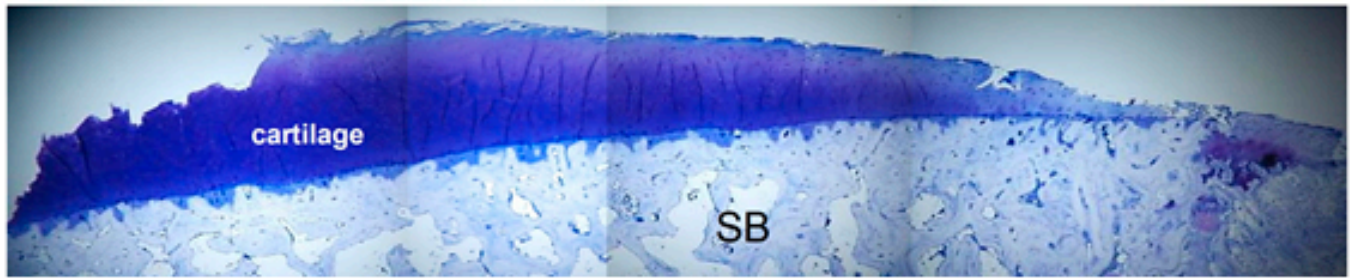

Figure 2. Diagrammatic overview demonstrating the influence of non-physiological load on articular cartilage composition and structure. (A) Safranin-O stained section of immature bovine articular cartilage, (B) schematic representation of articular chondrocyte morphology and cartilage disruption with increasing pathological load and (C) toluidine-blue -stained section of knee articular cartilage from a patient with end-stage osteoarthritis (OA) (adapted from [14]). SZ, superficial zone; MZ, middle zone; DZ, deep zone; CZ, calcified zone; SB, subchondral bone.

\section{Composition and Localisation of ECM Components Are Highly Organised in Articular Cartilage and Confer Biomechanical Functionality}

The ECM of articular cartilage is comprised largely of two matrix compartments, the fibrillar collagen network and the extrafibrillar matrix. These are connected by a number of perifibrillar adaptor proteins and collectively provide stability and structural integrity (reviewed in [15]).

\subsection{Collagens}

The collagen fibrils of articular cartilage are largely composed of type II $(>90 \%)$, XI $(\sim 3 \%)$ and IX $(\sim 1 \%)$ collagens $[16,17]$ and are densely packed and orientated to allow them to resist the forces imposed by articulation [18]. The N-terminal short arm of type IX collagen projects into the perifibrillar space to provide binding sites to other matrix molecules such as FN [4] whilst the long arm is orientated towards the fibril to allow covalent interactions with type II collagen and other type IX molecules [19-22]. Type III 
collagen which colocalises with type II collagen [23-25] and type IV $[5,26,27]$ is also found in small amounts within the pericellular matrix (PCM) and is thought to play a role in regulating fibril diameter and modifying existing fibril networks $[27,28]$. Type VI collagen anchors the chondrocytes to the ECM, mediating cell-matrix interactions and transducing mechanical cues-discussed in detail below [29-31].

\subsection{Proteoglycans}

The most abundant proteoglycan (PG) by mass in cartilage is aggrecan; it is heavily glycosylated with more than 100 negatively charged sulphated GAGs including chondroitin sulphate and keratan sulphate. Versican is also present as an aggregating chondroitin sulphate PG in developing cartilage but with levels declining with age [32,33]. Both aggrecan [34] and versican [32] form large aggregates, via link proteins, with the glycosaminoglycan (GAG) hyaluronan which is critical for the maintenance of the pericellular environment surrounding the cell [35]. These large aggregates attract solutes generating an osmotic swelling pressure which is critical to counteract compressive forces during movement [36]. Since versican interacts with fibrillin- 1 which binds latent TGF $\beta$-binding protein 1 [37], it has been proposed that versican plays a role in TGF $\beta$ signalling [32]. In addition to the large aggregating PGs, non-aggregating PGs are present including the small leucinerich proteoglycans (SLRPs), biglycan (BGN) and decorin (DCN) and fibromodulin. The PCM consists of high concentrations of the hyaluronan-aggrecan link protein complexes and BGN and DCN [38,39] and is associated with rapid rates of aggrecan turnover [40], proteoglycan deposition [41] and the greatest sensitivity to static and dynamic loads [42].

\subsection{Perifibrillar Adapter Proteins}

Perifibrillar adapter proteins, including matrilin-1-4 (reviewed in [43]), DCN [39,44], COMP [6,45] and type IX collagen [22,46], are essential for healthy cartilage, playing important roles in regulating fibril diameter in immature cartilage, stabilising the ECM network in adult cartilage and interconnecting the fibrillar and extrafibrillar matrix [43,44,47,48]. All four matrilins are expressed in adult cartilage at low levels and bind to various ECM components [49]; matrilin-3 forms complexes with matrilin- 1 and -4 that are linked via BGN and DCN to type VI collagen microfibrils (reviewed in [43]). Whilst individual matrilin knockouts have mild phenotypes with other matrilins compensating for their loss [50], quadruple knockout mice exhibit a severe osteoarthritic phenotype with age revealing a role for matrilins in protecting from spontaneous OA [49]. The importance of COMP has been highlighted by a number of studies which found that it catalyses fibril formation [51] and, in adult cartilage, stabilises the network [6] by binding to type IX collagen [6,52], matrilin-3 and $-4[45,46]$ and connecting the collagen network to aggrecan via BGN and DCN [53] (reviewed in [43]). The complex of collagen IX, matrilin-3 and COMP is essential for cartilage matrix stability since mutations in these genes cause multiple epiphyseal dysplasia with patients developing early-onset OA [54]. In addition, loss of type IX collagen results in reduced integration of COMP and matrilin- $1,-3$ and -4 into the ECM [46,55], a softer cartilage matrix [56] and increased fibril diameter [46,55].

\section{The Pericellular Matrix and Its Role in Chondrocyte Mechanotransduction}

Organisation of the chondrocytes within the tissue's ECM is central to its biomechanical functionality [39,57-61]. Articular cartilage ECM is split into two main areas: a PCM and a territorial matrix (TM)/interterritorial matrix (ITM) region (Figure 3). The highly specialised PCM is a $2-4 \mu \mathrm{m}$ thick region compositionally and structurally distinct from the surrounding ECM; chondrocytes encapsulated within the PCM collectively form the 'chondron'. Interestingly, chondrons are orientated relative to the direction of local mechanical strains and demonstrate a depth-dependent polarised morphology [39]. Experimental studies and theoretical models have demonstrated that the PCM facilitates the transduction of both biomechanical and biochemical signals to the residing chondrocytes [58-61], thereby regulating the process of mechanotransduction in the chondrocyte $[30,57,62-64]$. To 
facilitate this, the PCM is softer than the rest of the ECM $[39,65]$ but has a higher modulus than the cell [66] acting as a biomechanical buffer [67] to control the deformation applied to the cell [68]. In addition, the PCM regulates chondrocyte phenotype [69], with cell survival directly dependant on the interactions between the chondrocyte and the PCM [70,71], and acts as a biological reservoir sequestering growth factors and signalling molecules [72-75]. The unique structure of the PCM enables it to function in these important roles; it is rich in PGs (e.g., aggrecan, hyaluronan, DCN, perlecan, BGN), collagens (IX, VI collagen), basement membrane proteins (laminin, nidogens, collagen IV) and non-collagenous glycoproteins such as FN (reviewed in [76,77], and [39]; [44,61,62,78,79]) which interact forming a mesh-like structure $[77,80]$.

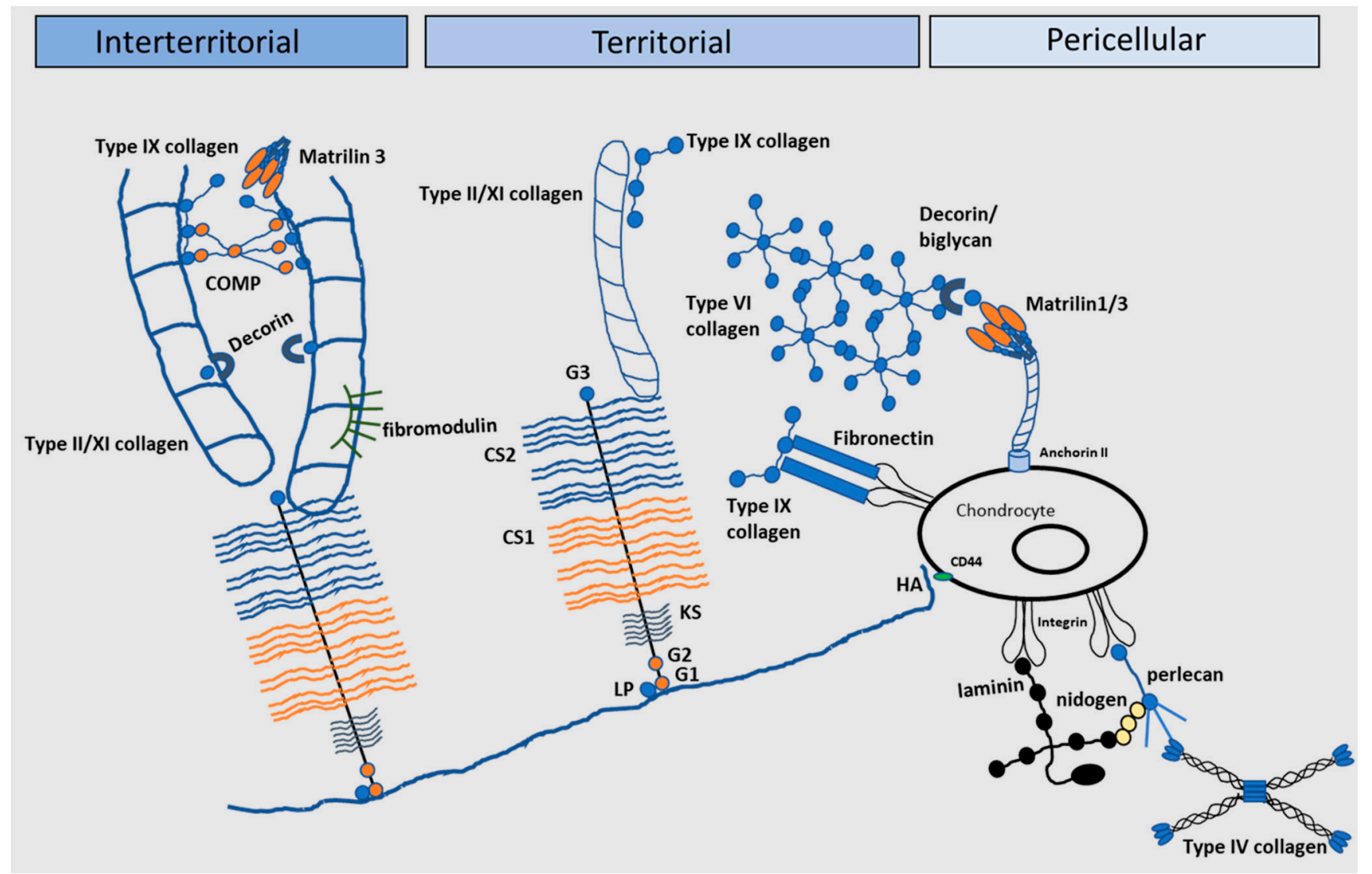

Figure 3. The extracellular matrix of articular cartilage. The extracellular matrix (ECM) of articular cartilage is comprised largely of collagen and proteoglycans, with smaller amounts of other non-collagenous proteins and glycoproteins. Large proteoglycan aggregates such as aggrecan interact with collagens and contain chondroitin sulphate (CS) and keratan sulphate (KS), covalently linked to hyaluronic acid (HA) by link protein (LP). Matrilin-1, -3 and -4, decorin, COMP and type IX collagen link the type II/XI collagen fibrils and mediate interactions between the collagen network and the aggrecan matrix (G globular) (Adapted from [81]).

The function of the PCM is defined by the presence of type VI collagen, a nonfibrillar collagen that forms a microfibrillar network to anchor the chondrocyte to the ECM $[29,30,82]$. It integrates with the surrounding ECM by binding to type II collagen, aggrecan and hyaluronan with links to BGN, DCN and type IX collagen $[44,78,82,83]$. In addition, it binds at numerous sites to the chondrocyte cell membrane via integrin receptors and the chondroitin sulphate proteoglycan neural/glial antigen 2 (NG2) [84,85] and thus mediates cell-matrix interactions facilitating transduction of biomechanical signals from the cartilage ECM (reviewed in [86]). The critical role of type VI collagen has been demonstrated by several studies whereby knockout or knockdown of the Col6a1 gene results in alterations in PCM structure and function $[30,87,88]$. Twomey et al. showed that 
Col6a1 knockdown results in a reduction in the expression of the genes encoding aggrecan, BGN and DCN during chondrogenesis [88] and knockout of type VI collagen in mice results in a reduction in the PCM elastic modulus [30]. Chondron formation in these mice occurs, but PCM stiffness is reduced resulting in aberrant buffering of loads applied to the cartilage [87].

Perlecan also plays an important role in mediating PCM organisation and mechanical stability (reviewed in $[89,90]$ ) colocalising with type VI collagen and affecting the PCM modulus [62,91]. It provides a pericellular reserve of inactive fibroblast growth factor 2 (FGF2) [92] which is released following deformation of the PCM and subsequent activation of downstream signalling pathways to modulate ECM homeostasis [73,92,93]. Other growth factors include connective tissue growth factor (CTGF) which is sequestered in a covalent complex with latent TGF $\beta$ by perlecan [94] and, more recently, hepatoma-derived growth factor (HDGF) which is heparan sulphate bound in the PCM [75]. The mechanism of FGF and HDGF release is thought to be due to a rapid flux in $\mathrm{Na}^{+}$that is displaced from the highly sulphated aggrecan-rich matrix on tissue compression [75,94]. Perlecan knockdown impacts PCM structure, composition and functional properties [95-97]. In mice devoid of perlecan $\left(\mathrm{Hspg}_{2}{ }^{\mathrm{C} 1532 \mathrm{Y}-\mathrm{Neo}}\right)$, encoded by the heparan sulphate proteoglycan-2 (Hspg2) gene, both in situ cell and ECM stiffness were significantly reduced which was hypothesised to be attributed to an alteration in ECM deposition resulting from disrupted growth factor signalling, e.g., FGF-2 and FGF-18 [97].

BGN and DCN localise to the N-terminal globular domain of type VI collagen [44] controlling its aggregation and are thus critical for the structural integrity of the PCM [74,98]. They act as functional bridges between type II and VI collagen to connect the PCM to the TM/ITM [44] and help control fibrillogenesis and growth factor bioavailability [72,74]. DCN knockdown results in an increase in aggrecan, BGN and sox 9 gene expression early in chondrogenesis and prevents the formation of a normal microfibrillar layer surrounding the cell [88]. In DCN null mice $\left(\mathrm{Dcn}^{-/-}\right)$, the modulus of the PCM is significantly reduced from 2 weeks of age onwards concomitant with the absence of a maturation-associated stiffening effect [65]; similar effects were also observed in the TM/ITM consistent with the finding that, at the tissue level, DCN loss results in a reduced cartilage modulus at $\geq 2$ weeks of age. Impairment of the PCM because of a loss of DCN also affected $\mathrm{Ca}^{2+}$ signalling and thus the chondrocytes response to load [65]. $\mathrm{Dcn}^{-/-}$cartilage has a significantly reduced aggrecan component and mild perturbations in collagen fibril nanostructure resulting in inferior biomechanical properties as evidenced by a decreased modulus and elevated hydraulic permeability [99]. Han et al. (2019) hypothesised that DCN is instrumental in increasing the adhesion between adjacent aggrecan molecules, as well as between aggrecan and type II collagen fibrils, and that DCN absence impairs biomechanical function by preventing physical linkages to increase aggrecan adhesion/assembly at the nanoscale level [99]. As well as their structural roles, DCN and BGN also sequester growth factors and signalling molecules. DCN binds TGF $\beta 3$, FGF2, tumour necrosis factor alpha (TNF $\alpha)$, platelet-derived growth factor (PDGF) and insulin growth factor 1 (IGF1) acting as a reservoir of biological factors that can subsequently modulate cellular homeostasis $[72,74,100]$. BGN also acts as a reservoir for the Wnt ligand Wnt3a and participates in canonical Wnt signalling via the cell surface receptor, low-density lipoprotein receptor-related protein 6 (LRP6) [101]. Although release of Wnt3a has not been shown to be triggered by mechanical load, there is evidence that the pathway is activated following injury [102]. Other cartilage ECM molecules including fibrillin and the glycoprotein fibulin localised to the PCM are also reported to sequester growth factors such as TGF $\beta 1$ [103]. Sequestration of TGF $\beta$ within the matrix is critical for cartilage health [104] since it mediates mechanical responses in cartilage [105] and is a potent inducer of cartilage ECM synthesis and suppressor of catabolism [106-108]. Indeed, high levels of TGF $\beta$ are found in normal articular cartilage but almost absent in OA [109].

Other 'basement membrane' components are also associated with the pericellular matrix including nidogen-1 and -2 [110], laminin $\alpha 1, \alpha 2, \alpha 4, \alpha 5, \mathrm{~b} 1$ and g1 [26,111] and type 
IV collagen [27,112]. Both nidogen-2 and laminin act as chondrogenic regulators increasing sox9 and promoting type II collagen, COMP and aggrecan synthesis and decreasing type I collagen synthesis [112]. Nidogen-1 and -2 mediate cell-matrix interactions, binding to integrin $\alpha \mathrm{V}$ and $\mathrm{b} 1$ in vivo [110].

The PCM subsequently integrates with the surrounding tissue, via a basket-like weave of fine collagen fibrils, PGs and FN forming the TM [113]. This chondroitin sulphaterich matrix protects the chondrocytes against mechanical stresses contributing to the ability of the matrix to withstand substantial loads $[39,114]$. The TM is located within an interterritorial matrix comprised of fibrillar and non-fibrillar collagens, PGs, laminins and FN which collectively contribute to mechanosensing to regulate chondrocyte function and cartilage homeostasis [115]. Alterations to ECM composition, particularly of PCM properties, can influence cartilage function inducing or progressing tissue degeneration and OA pathology.

\section{Mechanical Load Influences Articular Cartilage ECM Turnover}

Articular cartilage can respond to mechanical perturbations in the local tissue environment, sensing alterations in the magnitude or type of loading applied, and eliciting cellular behaviours to effect change. During normal physiological loading, a homeostatic balance of anabolic and catabolic activities is maintained ensuring the slow but consistent turnover of the PCM. However, following application of abnormal, non-physiological loading (excessive loading, joint trauma or malalignment), the balance of chondrocyte metabolism is disturbed resulting in dysregulation of PCM turnover and enhanced catabolism, cartilage degradation and onset of OA pathology (Figure 2B,C).

Articular chondrocyte mechanobiology has been investigated extensively over the past few decades, utilising both in vivo and in vitro models to establish the interplay of mechanical loading in conjunction with the structure and function of cartilage. In situ, the chondrocyte resides within a dynamic mechanical environment comprising a combination of compression, hydrostatic pressure, shear stress, osmotic stress and tensile strain. Typically, direct contact between opposing joint surfaces can yield dynamic compressive stresses of 5-6 MPa in the human knee during walking, and dynamic compressive stresses in the knee and hip can reach 10-20 MPa during activities such as climbing stairs [116]. Numerous studies have been undertaken to investigate the response of cartilage chondrocytes to these different loading parameters, whereby defined mechanical forces have been applied to chondrocytes in isolation or in situ and effects on ECM metabolism characterised.

\subsection{Compression}

\subsubsection{Dynamic Compression}

Maintenance of healthy articular cartilage relies on continuous turnover of the ECM which is achieved through a balance of biosynthetic and degradative events. This is attributed to the application of moderate compressive loads experienced during movement. In vivo, the static and dynamic stresses and strains that articular cartilage is subjected to are dependent on anatomical location within the joint and the specific activity being undertaken [117-120]. These compressive strains are not uniform through the tissue depth with $>50 \%$ experienced at the joint surface, $10-20 \%$ in the transitional zone and $<5 \%$ in the deep zone [121].

Elucidation of ECM collagen involvement in withstanding dynamic compressive strains $(20 \%, 0.25 \mathrm{~Hz})$ has indicated, at the nanoscale level, that the collagen fibrils exhibit a reversible reduction in the fibrillar D-period promoting a state of 'pre-strain' as well as an alteration in the degree of fibril orientation [122]. The reversible reduction in collagen fibril pre-strain has been attributed to a pressure-induced reduction in the hydrostatic swelling pressure in the ECM due to localised loss of water from the ECM. Furthermore, how the chondrocytes respond to dynamic compression is highly dependent on specific parameters including magnitude of load, frequency, strain-rate and loading history. Numerous studies in cartilage explants and chondrocyte-seeded scaffolds have demonstrated that 
following application of physiological magnitudes of dynamic compression ( 10-20\%), chondrocytes increase biosynthesis of ECM molecules, including proteoglycans [123-126], collagens [126,127], FN and COMP [127], which support tissue structure and function. Buschmann et al. also found that tissue regions experiencing high interstitial fluid velocities as a result of dynamic compressive loading correlated with enhanced aggrecan synthesis [125]. Furthermore, intermittent loading regimens were found to be superior in promoting ECM synthesis (reviewed in [128]) contributing to increased proteoglycan synthesis following short loading durations [129] and over several weeks of culture [126]. Chondrocyte-agarose constructs exposed to alternate days of intermittent dynamic stimulation $(2.5 \%)$ with days of free-swelling culture increased both equilibrium and dynamic moduli demonstrating the importance of physiological loading in promoting superior biomechanical properties of the ECM [130]. One mechanism by which compressive load induces ECM synthesis, in chondrocytes embedded in agarose, is via the regulation of transient receptor potential vanilloid 4 (TRPV4) channel function. TRPV4 is a non-selective $\mathrm{Ca}^{2+}$ channel that orchestrates osmotic-pressure-induced ECM turnover [131]. Application of compressive load ( $10 \%$ peak-peak sinusoidal $(7 \%$ offset), $1 \mathrm{~Hz}, 3 \mathrm{~h} / \mathrm{d}$ ) over a 4 -week period increased ECM accumulation enhancing sGAG and collagen production in chondrocytes, which was negated when TRPV4 activity was inhibited [132]; furthermore, a reduction in the equilibrium Young's Modulus for the chondrocyte-agarose constructs was observed indicating a role for TRPV4 in promoting mechanically induced ECM biosynthesis and conferring tissue material properties.

Physiological loading, via voluntary wheel running for 3 weeks, has been shown to regulate the expression of $\operatorname{Prg} 4$ in vivo, in the knee joints of knock-in mice expressing a

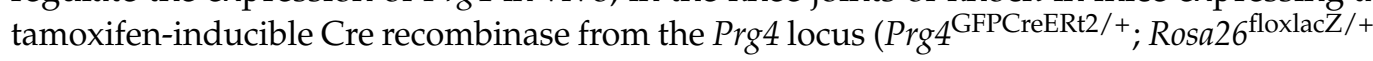
mice) [133]. A doubling in the number of articular chondrocytes expressing Prg4 was observed in the knee joints following the running regimen, with the greatest increase observed in the SZ cells of the tibial plateau, indicative that mechanical loading can activate downstream intracellular signalling pathways to induce Pgr4 expression. Ogawa et al. (2014) demonstrated that mechanically induced lubricin expression was mediated in a cyclooxygenase-2 (COX-2)-dependent manner, via increased prostaglandin E2 $\left(\mathrm{PGE}_{2}\right)$ production and phosphorylation of CREB concomitant with nuclear translocation of CREBregulated transcription coactivator 1 (CRTC1/2) to induce Prg4 transcription [133].

\subsubsection{Static Compression}

Depending on the activity and anatomical location within the joint, articular cartilage can also experience static compressive strains in vivo which can influence ECM homeostasis [117-120]. With sustained compression, the expulsion of water and ions induces indirect physicochemical effects such as streaming potentials, changes in pericellular $\mathrm{pH}$, osmolarity, fixed charge density and osmotic pressure which contribute to inhibiting ECM synthesis. Previous studies have demonstrated a magnitude-dependent reduction in aggrecan [134-136], link protein [137] and type II collagen synthesis [134-136] with increasing levels and duration of static compression. Intriguingly, hyaluronan synthesis was unaffected by static compression [137] implying that static compression does not inhibit all cellular activity, rather that it contributes to a mechanotransduction mechanism promoting spatial and/or temporal changes in specific ECM molecule biosynthesis.

Elucidation of ECM collagen involvement in withstanding static compressive strains has indicated at the nanoscale level the existence of a collagen fibril tensile pre-strain of approximately $1-2 \%$ [138]. A rapid reduction and recovery of the collagen pre-strain was found to occur during stress-relaxation and approximately $60 \mathrm{~s}$ after the onset of peak load ( $20 \%$ static strain); the initial reduction was attributed to disordering of the intrafibrillar molecular packing, concomitant with alterations in the axial overlapping of tropocollagen molecules within the fibril. The presence of this pre-strain phenomena was attributed to the osmotic swelling potential of the PGs as enzymatic removal of the chondroitin sulphate moieties on aggrecan disrupted the collagen fibril pre-strain and its transient response 
during the stress-relaxation phase [138], demonstrating the equivalent importance of both the collagen fibrils and PG aggregates in enabling cartilage biomechanical functionality.

\subsection{Shear Stress}

In vivo, cartilage that is regularly subjected to high levels of shear stress, i.e., patellar surface of femur and femoral condyles, exhibits a thicker SZ concomitant with a greater degree of collagen orientation compared to a region that is preferentially subjected to weight bearing, e.g., the tibial plateaus [139]. Fluid shear stress, involving the movement of fluid over a tissue that in vivo can result from pressure of the synovial fluid against the cartilage during joint movement, is known to influence the expression of several key ECM molecules. A systematic review of fluid shear studies demonstrated an overall increased production of type II collagen and aggrecan in chondrocytes under a variety of loading regimens [140]; the reported stimulation of ECM synthesis is likely attributed to improved diffusion and transport of nutrients facilitated by fluid flow. Furthermore, shear stress has been found to influence lubricin expression directly with application of dynamic shear (3\%) inducing its production and secretion, the latter effect still evident 3 days following load cessation [141]; shear-induced lubricin production can contribute to the low-friction bearing properties of the cartilage surface during joint movement. Lubricin secretion was also induced following exposure to a steady laminar non-pulsatile shear stress $\left(7.6 \mathrm{dyn} / \mathrm{cm}^{2}\right)$ in SZ chondrocytes only [133]; no effect was observed from chondrocytes isolated from cartilage mid-zone substantiating its function in joint surface lubrication. Interestingly, shear-induced lubricin production is mediated via the up-regulation of $\mathrm{PGE}_{2}$ and secretion of extracellular ATP via $\mathrm{P} 2 \mathrm{X} 7$ and $\mathrm{P} 2 \mathrm{Y} 2$ receptor engagement in a $\mathrm{Ca}^{2+}$-dependent manner [133].

An alternative form of shear, referred to as tissue or contact shear, is instigated by solid-on-solid contact. Application of tissue shear (3\%) was stimulatory inducing both protein and PG biosynthesis in cartilage explants, indicating that chondrocytes can respond to tissue shear stress inducing ECM synthesis in the absence of macroscopic tissue-level fluid flow, via deformation of the chondrocytes and associated PCM [142].

\subsection{Hydrostatic/Osmotic Pressure}

A high GAG content is essential to the load-bearing requirements of joints conferring the tissue with the properties of low hydraulic permeability and high swelling pressure [143]. The high PG content in the cartilage ECM providing negatively charged sGAGs attracts cations to maintain an electroneutral environment and, in so doing, creates an osmotic gradient against the synovial fluid. This osmotic gradient imparts a swelling pressure enabling the PGs to expand within the constraints imposed by the surrounding collagen network. Following joint activity, water is exuded from the compressed cartilage, but during the initial stages of loading, the low hydraulic permeability leads to fluid pressurisation, increasing the hydrostatic pressure within the tissue. Following load removal, water is re-imbibed into the cartilage restoring the tissue's original physical properties. However, with increasing load magnitude or duration of load application, not only is the tissue subjected to hydrostatic pressure, but the exudation of water and ions can alter the biophysical environment resulting in alterations to local $\mathrm{pH}$ and osmolarity, as well as inducing fluid flow and streaming potentials [144]. It remains to be fully elucidated whether in vivo the chondrocytes react to alterations in hydrostatic pressure via tissue deformation or whether they are responding to alterations in the local biophysical environment; evidence from in vitro studies indicates that the chondrocytes are highly sensitive to both direct, i.e., deformation, and indirect signals, i.e., biophysical cues, to effect cartilage turnover.

For example, 'physiological' hydrostatic loading regimens have previously been shown to significantly enhance PG synthesis in cartilage [145] and articular chondrocytes $[146,147]$ and collagen synthesis in chondrocytes [146,147]; however, application of 'non-physiological' pressures (i.e., increased magnitude and loading cycle duration) resulted in reduced biosynthetic rates $[145,146]$. A recent meta-analysis corroborated these findings demonstrating a diversity in chondrocyte response with both anabolic 
and catabolic behaviours, with a magnitude within the mid-high physiological range of cartilage (5-10 MPa) enhancing PG synthesis [148].

Hydrostatic pressure can also act indirectly by modulating biophysical cues which influence solute concentrations around the resident chondrocytes in the ECM. In vitro studies have shown that chondrocytes respond to changes in osmolarity via transient increases in intracellular $\mathrm{Ca}^{2+}$ to effectively regulate ECM synthesis and chondrocyte metabolism [149]. Articular chondrocytes exhibited a frequency dependent intracellular $\mathrm{Ca}^{2+}$ transient in response to dynamic osmotic loading culminating in increased aggrecan transcription, mediated via cytoskeletal actin re-organisation [149]. $\mathrm{Ca}^{2+}$ inhibitor studies have demonstrated the differential involvement of $\mathrm{Ca}^{2+}$ entry pathways in response to static and dynamic hypotonic loading to modulate ECM biosynthesis. Importantly, the TRPV4 channel is not only osmotically sensitive [131] but has also been demonstrated to be activated in response to tensional force, acting on cell-integrin-ECM adhesions in chondrocytes [150]. Further evidence has inferred that mechano-osmotic signalling through TRPV4 activation is mediated through the mechanical properties of the cartilage ECM, specifically type VI collagen in the PCM [31]. In the absence of type VI collagen (Col6a1 ${ }^{-/-}$mice), chondrocytes presented a heightened TRPV4-mediated response to hypoosmotic stress as compared to age-matched wild-type controls at 2 months of age [31]. The observed increase in hypo-osmotic-stress-induced cell swelling was associated with a loss of mechanical properties in the Col6a1 ${ }^{-/-}$PCM, suggestive that type VI collagen is important in regulating the mechanical properties of the PCM, cell swelling and osmotically induced signalling mechanisms. Clearly, type VI collagen plays an instructive role in regulating the transduction of mechanical and physicochemical signals from the cartilage ECM to the chondrocyte, via the critical involvement of the PCM $[63,151]$.

In addition to TRPV4, TRPV2 has been shown to be important in the maintenance of articular cartilage homeostasis [152]. Cartilage specific knockout of TRPV2 (Trpv2 $\left.{ }^{-/-}\right)$in mice resulted in the development of $\mathrm{OA}$ and three forms of mechanical stimulation (hypoosmotic stress, fluid flow, stretch) invoked $\mathrm{Ca}^{2+}$ influx via up-regulation of lubricin and activation of CaMKK-Creb signalling which was abolished in Trpv2 ${ }^{-/}$chondrocytes [152].

\subsection{Tensile Strain}

In vivo, tensile strains are generated tangential to the articulating joint surface and at the interface between cartilage and bone. During joint articulation, tensile strain is experienced by the articular chondrocytes, principally arising as a consequence of compressioninduced cellular deformation, i.e., a reduction in cell height accompanied by an increase in cell width [153]. Chondrocytes subjected to $10 \%$ tensile strain in vitro increased COL1A1 expression concomitant with a significant reduction in COL2A1 and ACAN transcript levels [154]; application of a lesser strain of $5 \%$ elicited no effect on the expression of these ECM molecules. This contrasts to our own study where a $7.5 \%$ strain increased chondrocyte type II collagen and aggrecan mRNA levels $4 \mathrm{~h}$ following strain cessation [155]. Not surprisingly, tensile strains are found to elicit varying chondrocyte responses which is largely dependent on the magnitude and frequency of strain applied (comprehensively reviewed in [156]).

A systematic review of the literature investigating the influence of cyclic tensile strain (CTS) on chondrocyte metabolism identified that, overall, longer loading durations (3-6 h) increased type II collagen and aggrecan transcript levels [156]; however, this was strainmagnitude-dependent with enhanced transcription of ECM molecules at higher strains (10-24\%). Extended loading episodes (16-72 h) were also found to be detrimental to matrix synthesis, resulting in transcriptional inhibition of type II collagen and aggrecan. Such biosynthetic patterns were also largely evidenced at the protein level (reviewed in [156]). Interestingly, the biosynthetic response was dependent on the ECM substrate the chondrocytes were cultured on; chondrocytes seeded on FN enhanced PG synthesis in response to $7 \%$ tensile strain [157]; seeding on type I collagen elicited no response 
indicating how important integrin-mediated attachment of chondrocytes to their native ECM is in transmitting mechanical signals.

Other ECM molecules are also regulated by tensile strain, with 5-9\% strain increasing transcript levels of lubricin ( $<48 \mathrm{~h}$ [158]), FN (<24 h [159]) and matrilin-1 (<48 h [160]). A concomitant induction of lubricin protein was also observed followed a $7 \%$ strain stimulus, but a significantly higher strain (21\%) inhibited its expression [161], illustrating the concept that moderate loading facilitates joint lubrication and low friction movement, whereas excessive loading impacts lubricin production and functionality. Furthermore, lubricin and COMP mRNA levels were also elevated in response to $9 \%$ tensile strain in chondrocytes embedded in 3D alginate constructs [161], illustrating the critical role of the mechanical stimulus in effecting changes to ECM composition to promote joint function.

In matrilin-1-deficient ( $\left.\mathrm{Matn}^{-1^{-}}\right)$chondrocytes, strain-induced transcription of Acan and Col2a1 was abolished [162]. Furthermore, load-induced downstream activation of Indian Hedgehog (Ihh) signalling was suppressed in engineered chondrocytes devoid of functional matrilin-3 [160], indicating the importance of this PCM molecule in mediating mechanotransduction. Interestingly, overexpression of the matrilins also adversely affected chondrocyte mechano-signalling, which was attributed to a likely direct impact on PCM mechanical properties or a possible saturation of ECM binding sites by their ligands [160]. Such evidence suggests that load-mediated modification of PCM composition has the potential to modify the 'threshold' of chondrocyte mechanosensing, i.e., functional adaptation to load applied.

Under tensile load, cartilage is reportedly much stiffer in the SZ compared to the deep zone [163]. Using the technique of polarisation sensitive second harmonic generation (P-SHG), the relationship between macroscopic strain applied to cartilage and the submicron response of the collagen fibrils was investigated [164]. As applied strain increases $(0-16 \%)$, orientation of the collagen fibrils preferentially aligned with the direction of strain and became more organised in the SZ of cartilage; this increase in local organization of the collagen fibrils in the SZ weakly correlated with tensile modulus suggestive that higher forces are required to generate these changes in situ [164].

\subsection{Injurious Loads}

Upon injurious loading induced by non-physiological loading or an acute traumatic injury, a key feature is the early inhibition of PG synthesis concomitant with the rapid loss of endogenous PGs from the ECM proceeded by inhibition of collagen synthesis and degradation of the collagen network (Figure 4). In vitro studies have demonstrated that abnormal, i.e., super-physiologic loading magnitudes ( $>20 \%$ compressive strain) do not induce ECM synthesis [127], whilst static or very low frequency loading inhibits ECM synthesis [134]. However, injurious compression shifts cartilage chondrocyte-mediated ECM metabolism to a catabolic phenotype with a magnitude-dependent increase in tissue swelling, GAG loss, degradation of the collagen fibril network and a decreased explant dynamic stiffness $[165,166]$. 


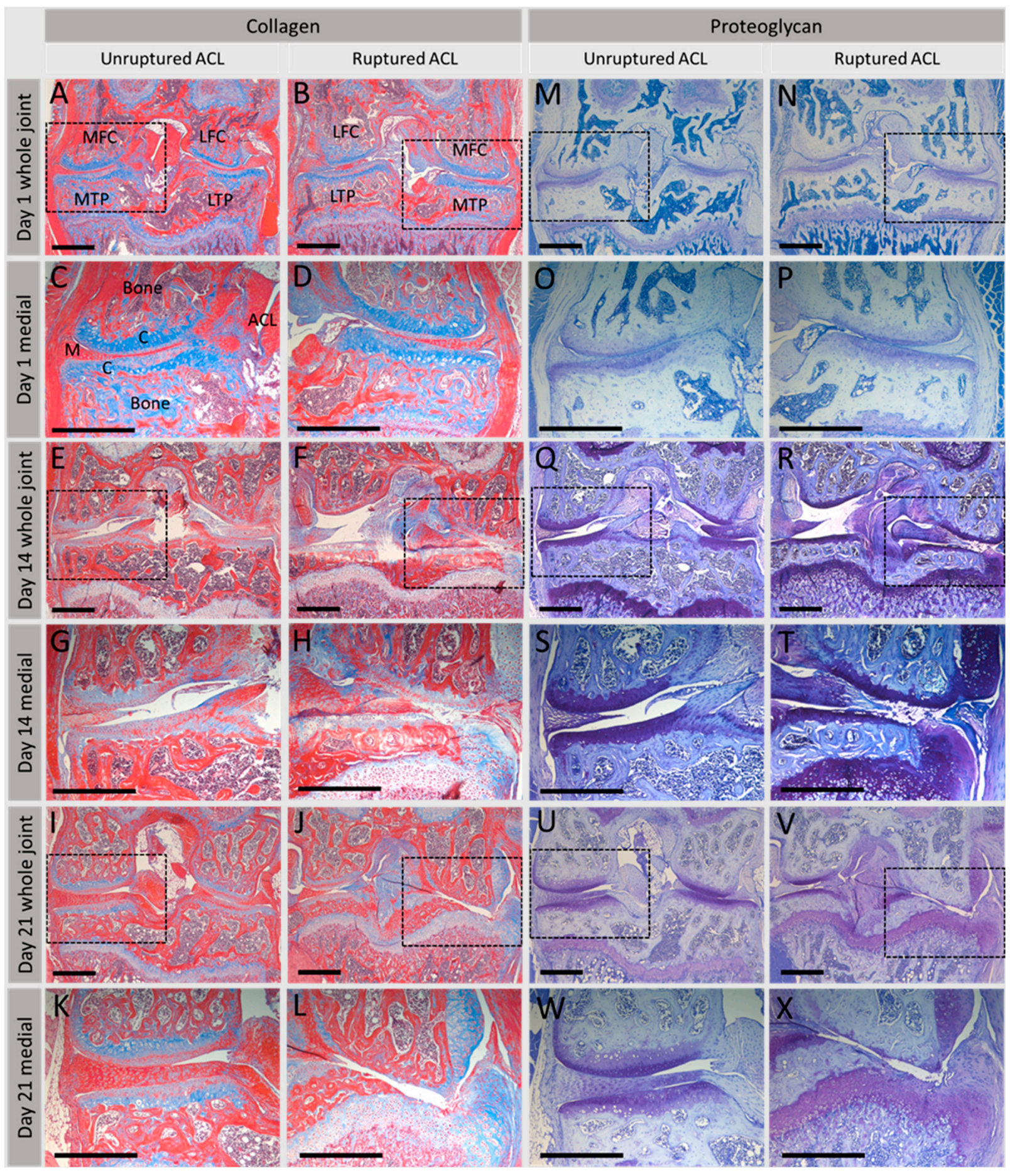

Figure 4. Effect of injurious load on articular cartilage integrity in the synovial joint. Collagen and proteoglycan distribution in an in vivo non-surgical murine model of post-traumatic OA following rupture of the anterior cruciate ligament (ACL) [167]; knee joint integrity was assessed at days 1, 14 and 21 post-rupture and compared to mice with an intact ACL, i.e., unruptured controls. (A-L) show collagen (blue) distributed throughout cartilage and bone. On day 1, collagen is located evenly throughout cartilage (A-D); however, at day 14 post-rupture (F and H), cartilage fibrillation is evident with loss of collagen, followed by complete loss by day 21 (J,L). Proteoglycan distribution (dark blue, (M-X)) shows a similar distribution throughout the cartilage, evenly distributed at day 1 (M-P) but gradual loss as joint damage begins to occur at $14(\mathbf{R}, \mathbf{T})$ and 21 days $(\mathbf{V}, \mathbf{X})$ post-ACL-rupture. Trichrome stain kit (Abcam, ab150686) was used for collagen staining, toluidine blue for proteoglycans. MFC, medial femoral condyle; LFC, lateral femoral condyle; MTP, medial tibial plateau; LTP, lateral tibial plateau; M, meniscus; C, cartilage. Dashed boxes indicate higher magnification medial compartment images directly below. Scale bars: $500 \mu \mathrm{m}$. 
Not only does injurious load impact PG and collagen production, it also regulates the synthesis and/or secretion of other molecules necessary for articular cartilage function. Secretion of lubricin, essential in facilitating boundary lubrication to provide a low coefficient of friction, was found to be increased from the uppermost region closest to the articular surface following mechanical injury $(50 \%$ compressive strain applied at a strain rate of $100 \% / s$ ) which was observed at the gene level too [168]; increased lubricin expression was found to be a transient response to injurious compression [168]. Concomitant with increased lubricin secretion, injurious load induced cell death, altered tissue architecture and reduced PG and collagen content. Furthermore, the cartilage explants displayed an increased coefficient of friction demonstrating that injurious load significantly compromises tissue function [168]. Application of 60 cycles of injurious compressive load (20 and $50 \mathrm{~N})$ on rat knees in vivo resulted in a transient reduction in lubricin within the lesions that formed on the lateral femoral condyles [169]. The detrimental effects of high-magnitude, high-strain-rate injurious loading regimens are thought to result as a consequence of cellular damage, such as chondrocyte apoptosis and necrosis [170]. Interestingly, following injurious load, the surviving cell population lacks a biosynthetic response to physiologic levels of dynamic loading [166], indicative of a sustained modification of chondrocyte mechanotransduction.

In vivo models have also provided considerable evidence for the consequence of injurious load on cartilage ECM metabolism. Significant, early loss of PGs was observed in our in vivo non-surgical murine model of joint degeneration whereby a single compressive load ruptures the anterior cruciate ligament rupture (ACL) inducing abnormal loading of the joint cartilage (Figure 4) [167]. Following mechanical injury, localised inflammation preceded the extensive loss of ECM proteoglycans and collagen that was observed over time, replicating a post-traumatic osteoarthritis (PTOA) phenotype.

This dramatic reduction in cartilage ECM content following mechanically mediated joint injury has been correlated with significant effects in the PCM. Using the destabilisation of the medial meniscus (DMM) murine PTOA model, Chery et al. (2020) observed a decrease in the mechanical properties of the PCM, although PCM composition was maintained; type VI collagen, perlecan and BGN remained localised to the PCM at 8 weeks, concomitant with reduced aggrecan content [171]. A significant reduction in the indentation modulus was observed as early as 3 days post injurious load suggestive that PCM degradation began quickly after this insult and preceded changes in the further-removed territorial and interterritorial ECM. However, over the 8 weeks period, the progressive reduction in indentation modulus for the PCM was also detected in the other regions of the ECM. Thus, alterations to the PCM induce a positive feedback loop that reduces protection to chondrocytes and induces OA [171].

An accelerated OA phenotype was reported in both DCN-null $\left(\mathrm{Dcn}^{-/}\right)$and inducible DCN knockout $\left(D c{ }^{i K O}\right)$ mice subjected to medial meniscus destabilisation [172]. Induction of DCN ablation following skeletal maturity to prevent confounding influences of joint growth on outcome measurements demonstrated that $\mathrm{DCN}$ absence $\left(D c n^{i K O}\right)$ accelerated sGAG loss accompanied by the formation of surface fissures but did not significantly affect indentation modulus [172]. DCN loss accelerated aggrecan depletion, thereby impairing aggrecans' protection of the collagen fibrillar network following mechanical insult; these findings indicate the importance of DCN in promoting ECM structural integrity by providing a 'physical linker' to increase molecular adhesion between the ECM components.

Interestingly, following PTOA induction (DMM model) in inducible BGN $\left(B g n^{i K O}\right)$ mice, the degree of OA was comparable to control mice and not as severe as the phenotype observed in the $\left(D c n^{i K O}\right)$ mice [173], implying that BGN loss has a lesser impact than DCN on DMM-induced cartilage degeneration. Utilisation of the DCN/BGN compound $\left(\mathrm{Dcn} / \mathrm{Bg} n^{i K O}\right)$ knockout mouse in this study indicated that following DCN loss, the accompanying loss of BGN did not aggravate OA progression. However, a significantly higher modulus was reported in the $\mathrm{Dcn} / \mathrm{Bg} n^{i K O}$ mice after meniscal destabilisation which was attributed to greater cartilage erosion [173]. The differential phenotypes following DCN or 
BGN ablation may be explained by differences in their localisation, binding activities and response to joint destabilisation and inflammation; furthermore, although BGN is critical in maintaining cartilage PCM integrity, its concentration and distribution is unaffected in the DMM model [171] suggesting that it does not contribute significantly to OA pathogenesis following meniscal destabilisation.

The initiating injurious mechanical stimulus clearly influences the behaviour of the tissue and the resultant downstream biosynthetic responses within the cartilage; interestingly, $\mathrm{Dcn}^{-/-}$mice were protected from the development of OA induced by forced exercise through treadmill running [174]. Reduced PG staining was only observed in the SZ, and the characteristic surface roughening and fibrillation observed in the wild-type mice was absent in the $\mathrm{Dcn}^{-/-}$mice. This evidence would initially suggest that DCN deficiency improves biomechanical functionality, protecting against cartilage degeneration; however, increased protein levels of TGF $\beta 1$, Chst11 (sulphotransferase enzyme which catalyses formation of $N$-acetylgalactosamine-4-sulphate in chondroitin sulphate moieties) and chondroitin-4sulphate were also observed in $\mathrm{Dcn}^{-/-}$mice following forced exercise [174]. The TGF $\beta$ superfamily members, which DCN can bind and functionally modulate, are known to be imperative in regulating cartilage homeostasis [175]. Therefore, it has been hypothesised that a compromised sequestration of TGF $\beta 1$ in the $\mathrm{Dcn}^{-/-}$mice enhances active TGF $\beta 1$ availability, promoting sulphation of GAGs and imbibition of water, to augment tissue biomechanical properties and delay load-induced cartilage degeneration [174]. The divergence in response of $\mathrm{Dcn}^{-/-}$mice to abnormal loading such as forced running versus meniscal destabilisation might be due to the induction of an initial inflammatory response in the DMM model, which is absent following forced exercise; however, this remains to be confirmed.

Utilising an alternative model of PTOA, involving the transection of the anterior cruciate ligament and medial collateral ligament, in tenascin-C $\left(\mathrm{Tnc}^{-/-}\right)$knockout mice, the extent of cartilage degeneration was accelerated relative to wild-type mice, suggestive that tenascin- $C$ is ordinarily involved in protecting against cartilage destruction [176].

Induction of DMM in matrilin-1-deficient mice $\left(\mathrm{Matn1}^{-/-}\right)$significantly reduced Acan and Col2a1 transcript levels, concomitant with greater erosion of the femoral cartilage relative to DMM-induced wild-type mice [162]; the pattern of erosion differed between the mice with irregular and substantial degenerative ECM changes predominating in the Matn $1^{-/-}$mice, along with more significant ECM disorganisation. Interestingly, these histological effects were not observed in uninjured $M a t n 1^{-/-}$mice indicating that the mechanical insult initiates cartilage degeneration and that the $M a t n 1^{-/-}$chondrocytes are incapable of adapting to this injurious load [162].

Injury and deleterious load results in the release of sequestered growth factors from the PCM followed by activation of downstream signalling pathways that modulate ECM homeostasis [93]. FGF2, HDGF and CTGF are all released upon injurious cutting of cartilage [75,92,94]. In addition, supra-physiological compression [177] and tissue shear [105] also promote latent TGF $\beta 1$ release from cartilage rapidly inducing Smad signalling which can impact ECM biosynthesis [175]. A recent study has shown that compression-induced growth factor release occurs preferentially in areas of low matrix stiffness such as from the PCM in the SZ resulting in SMAD2 phosphorylation indicative of TGF $\beta$ activation [75]. The study found that growth factor release following injury was due to a shift in the matrix $\mathrm{Na}^{+}$ concentration and hypothesised that the SZ selectively loses water, causing a local increase in the concentration of free $\mathrm{Na}^{+}$, and this drives growth factor release when compression is applied. These findings would explain why OA cartilage loses its ability to repair due to the severe loss of PG and the subsequent inability to release growth factors upon injury. Interestingly, the absence of loading rapidly reduced TGF $\beta 1$ signalling in chondrocytes, thought to be due to effective sequestration of TGF $\beta 1$ in the ECM, which could be rescued upon the re-introduction of dynamic compression [178], intimating how ECM components can self-regulate cartilage ECM homeostasis.

Irrespective of the loading stimulus applied to articular cartilage, the mechanosignalling process is reliant on stimulation of mechanoreceptors localised to the chon- 
drocyte membrane including integrin receptors, ion channels and primary cilia (reviewed in [179]). More recently, mechanically activated Piezo ion channels, Piezo1 and 2, have accrued much interest following reports of their involvement in chondrocyte mechanotransduction in response to hyper-physiological and injurious loads [180-182]. Following mechanically induced ECM deformation and stimulation of cell surface mechanoreceptors, activation and/or suppression of intracellular signalling pathways elicit downstream events to regulate chondrocyte response; this is beyond the scope of the current review but has been extensively discussed in $[179,183,184]$.

\section{Bidirectional Reciprocity Involves Alterations to the ECM Due to Mechanically Mediated Cell Behaviours}

The PCM is instrumental in transducing biomechanical signals to the chondrocytes, influencing cell behaviour such as metabolism, inflammatory cascades and intracellular signalling events to effect ECM remodelling. Irrespective of the loading stimulus applied to articular cartilage, the mechano-signalling process is reliant on stimulation of mechanoreceptors localised to the chondrocyte membrane including integrin receptors, ion channels and primary cilia (reviewed in [179]). More recently, mechanically activated Piezo ion channels, Piezo1 and 2, have accrued much interest following reports of their involvement in chondrocyte mechanotransduction in response to hyper-physiological and injurious loads [180-182]. Following receptor engagement and/or activation of ion channels, the biomechanical signal is transduced via assembly of focal adhesion complexes involving talin, vinculin and other structural and scaffolding proteins which result in cytoskeletal network re-organisation $[185,186]$. It has been well documented that the cytoskeleton acts as a conduit connecting the ECM to the nucleus, thereby facilitating dynamic and reciprocal interactions between the matrix and the nucleus to orchestrate gene expression and regulation of tissue homeostasis [187]. Re-organisation of the actin cytoskeleton has been shown to activate a number of downstream signalling cascades including Rho GTPases [188,189], mitogen-activated protein kinases (MAPKs) [190-192], phospholipase C [193] and calcium/calcineurin [149,194,195] to name but a few which converge in the nucleus to induce transcriptional responses that influence cell behaviours, PCM/ECM remodelling and ultimately tissue properties. Active Rho GTPase signalling results in the nuclear translocation of mechanosensitive Yes-associated protein (YAP) and transcriptional co-activator with PDZ-binding motif (TAZ) to initiate transcriptional events in the regulation of tissue homeostasis $[189,196]$.

Furthermore, studies have implicated a role for the nucleus in directly transducing a biomechanical signal via the linker of nucleoskeleton and cytoskeleton (LINC) complex [197]. The LINC complex, localised to the nuclear membrane, binds to all three cytoskeletal proteins and in particular to the intermediate filament lamin A which anchors chromatin to the nuclear lamina (comprising lamins A and C) [198] providing a structural pathway for force transmission from the cell surface to the chromatin [199]. As lamins A and C are located at the nuclear periphery, in addition to the nuclear interior, they associate with both hetero- and transcriptionally active euchromatin [200] providing a mechanism by which mechanical load can regulate gene transcription [201]. Increased expression of type II collagen [126,154,156,161], aggrecan [123-125,154,156], other PCM/ECM molecules [133,158-161] and anabolic growth factors, e.g., TGF $\beta 1[75,92,94,175]$, has been demonstrated in response to physiological load, whereas non-physiological load induced expression of pro-inflammatory cytokines $[167,202,203]$ and proteolytic enzymes $[167,202,204]$. Clearly, mechanically mediated transcriptional induction of key mediators of either chondrocyte matrix biosynthesis or degradation influences the extent of cartilage remodelling which has the potential to impact tissue properties and thus the bidirectional reciprocity of the chondrocytes with their surrounding PCM/ECM environment. Activation and/or suppression of specific intracellular signalling pathways that elicit downstream events to regulate chondrocyte response is beyond the scope of the current review but has been extensively discussed in $[179,183,184]$. 


\section{Consequences of Articular Cartilage ECM Degeneration on Mechanical Integrity}

Interaction of ECM molecules with chondrocytes regulates cell behaviour and the remodelling process; furthermore, proteolytic degradation of cartilage ECM components generating breakdown fragments can, in turn, activate or inhibit additional signalling pathways. Reciprocal engagement of the cells with the surrounding ECM can thus impact tissue homeostasis and, if this process becomes dysregulated, results in cartilage pathology. Mechanical loading has been reported to increase expression of proteolytic enzymes, including the matrix metalloproteinases (MMP) and aggrecanases (ADAMTS) responsible for degradation of collagen and PGs in the ECM [205]. Expression and activation of the collagenases MMP 1 and 13 were increased in vivo in cartilage exposed to supraphysiological compression [206] and excessive running [207], correlating with in vitro observations demonstrating enhanced expression in chondrocytes exposed to increased fluid shear [208].

\subsection{Mechanically Mediated Degradation of Key ECM Components Can Result in Accumulation of Bioactive Breakdown Fragments}

One of the consequences of enhanced proteolysis is the generation of bioactive breakdown fragments. Key ECM breakdown fragments detected in the cartilage matrix become endogenous catabolic factors activating pro-inflammatory pathways and potentiating further joint damage [209] (reviewed comprehensively in [210]). These extracellular damage-associated molecular pattern molecules (DAMPs) include those derived from type II collagen [211], fibromodulin [212], hyaluronan [213], tenascin C [214], aggrecan [215] and FN $[204,216]$. DAMPs are increased in knee OA compared to the hip and are therefore thought to be generated due to increased mechanical stress on the joint [217]. They are also released following impact loading of chondrocytes [170]. The biological activity of these DAMPs goes through pattern recognition receptors including Toll-like receptors (TLRs) to initiate downstream signalling cascades leading to the activation of several transcription factors, such as $N F \kappa B$, key regulators of the inflammatory response. The downstream consequence of this is the release of matrix-degrading enzymes such as MMPs and ADAMTSs and pro-inflammatory cytokines. Degradative fragments of type II collagen occur in normal and in OA cartilage and modulate the expression of several MMPs in articular cartilage chondrocytes with the potential to initiate catabolic pathways [211]. Injurious loading, via a single impact trauma to cartilage in vitro, induces the production of FN fragments concomitant with increased MMP3 levels, potentiating a positive feedback loop to sustain cartilage ECM damage [204]. Increased FN fragment levels have also been detected in the cartilage and synovium of patients with OA $[218,219]$. Catabolism of SLRPs has also been linked to compromised articular cartilage integrity with an increase in the release of soluble, fragmented BGN into the synovial fluid in late-stage OA being reported [220]. This was shown to accelerate PG and collagen loss in cartilage in vitro through elevated NFKB activities, an effect not observed with DCN. Melrose et al. also reported increased fragmentation of SLRPs including DCN, BGN, fibromodulin and lumican in OA knee tissue [221]. Interestingly, a recent study has shown that an aggrecan 32-mer fragment directly activates TLR2 on joint nociceptors and is an important mediator of the development of OA-associated joint pain [222]. Lee et al. also found that an aggrecan 32-mer fragment increased Mmp13 and Adamts5 mRNA expression and decreased Col2A1 and Acan mRNA through TLR-2- and NFKB-dependent signalling [215]. Clearly, mechanically mediated degradation of key ECM components can result in accumulation of bioactive breakdown fragments and has the potential to initiate pro-inflammatory signalling pathways, further exacerbating cartilage degeneration and loss of functionality.

\subsection{Mechanically Mediated Inflammation Promotes Cartilage Degeneration}

Both mechanical injury and the generation of bioactive breakdown fragments can induce an inflammatory response in the cartilage resulting in tissue degeneration. Furthermore, the invoking of a local inflammatory response in combination with continued 
application of injurious loading can exacerbate this degradative phenotype. Early in vitro studies demonstrated that PG loss induced by injurious mechanical compression was markedly increased when cartilage was simultaneously exposed to pro-inflammatory cytokines, i.e., interleukin- $1 \alpha$ (IL-1 $\alpha$ ) or TNF $\alpha$, indicative of a synergistic interaction in inducing cartilage degradation [223]. Other studies have also reported on the synergistic interaction of mechanical injury with TNF $\alpha$ and IL-6 with its soluble receptor (sIL-6R) in mediating PG degradation in cartilage [203]; the combination of mechanical injury and $\mathrm{TNF} \alpha$ only induced IL-6 production in chondrocytes, the expression of which was found to contribute significantly to the PG loss observed, and clearly evidenced how such a response can propagate 'follow-on signalling loops' initiated through interplay of mechanical and cytokine stimulation [203]. Induction of IL-6 following mechanical injury was also observed in cartilage from two separate in vivo models of PTOA studies, concomitant with elevated levels of both aggrecanase and MMP transcripts [167,202].

Interplay of mechanical injury and cytokines is pivotal to cartilage degeneration. Inhibition of IL-1 signalling, via administration of an IL-1 receptor antagonist (IL-1Ra), abrogated the inhibitory effect of injurious compression (static) on PG synthesis in cartilage in vitro [224]. Intra-articular administration of IL-1Ra in a murine model of PTOA (moderate closed articular fracture of tibial plateau) significantly reduced serum IL-6 concentrations and inhibited cartilage degeneration and synovial inflammation in vivo [225], substantiating a role for mechanical-injury-mediated inflammation in promoting cartilage matrix catabolism.

Recently, a putative mechanism of action for IL-1 engagement has been postulated to involve TRPV4 activity; dynamic compression induced transcription of IL-1R was suppressed following exposure to a TRPV4 agonist (and enhanced following TRPV4 antagonist) in ATDC5 chondrocytes [226]. It has been hypothesised that excessive compressive stress may impair TRPV4 function via regulation of cell volume, resulting in increased production of IL-1R, as well as ADAMTS-4 transcription, potentially initiating PG loss and adversely affecting interstitial osmotic pressure [226]. Furthermore, as TRPV4 has been shown to be intimately involved with type VI collagen in the PCM [31], PCM mechanical properties might subsequently be affected.

Interestingly, moderate dynamic compression was found to counteract the degradative behaviours observed in vitro when cartilage was exposed to injurious load in combination with the cytokines TNF $\alpha$ and IL-6 with its soluble receptor (sIL-6R) [227]; dynamic strains $<20 \%$ inhibited the pro-catabolic response of cartilage to injurious load and cytokine challenge by abolishing sGAG loss and aggrecanase activity [227]. More recently, similar observations were reported for the in vitro application of dynamic tibial axial loading (TAL) to counteract the inflammatory response to injurious impact with significant suppression of IL-1 $\beta$ and TNF $\alpha$ transcription mediated by injurious impact [228]. Such studies demonstrate the potential of using physiological loading regimens to mitigate the degenerative phenotypes induced by injurious mechanical loads, thereby conferring protection to cartilage structure and functionality.

\subsection{Effect of ECM Degeneration on Mechanical Properties of Cartilage}

An intact ECM has been shown, by several studies, to be critical for conferring cartilage mechanical properties with degenerated cartilage resulting in decreased tensile modulus [229] and decreased shear modulus [230]. Application of compressive load to in vitro cartilage explants enzymatically depleted of either collagen or PGs had little effect on strain distribution, as measured using displacement-encoded MRI during cartilageon-cartilage cyclic compression [231]. However, depletion of both molecules significantly increased axial, transverse and shear strain components, particularly in the SZ of the medial compartment contact region [231]. Loss of PGs, fibrillation of the collagen network and a switch from type II to type I collagen production in OA (reviewed in [232]) compromises the compressive and tensile properties of the tissue [233]. Interestingly, alterations in the biomechanical properties of knee joint cartilage from Col9a1 ${ }^{-/}$mice have been reported; 
decreased cartilage moduli in knee joint cartilage under both compression (E) and swelling configurations reflected a loss of matrix stiffness by 6 months of age in Col9a1 ${ }^{-/-}$mice. Loss of matrix stiffness suggests damage to the collagen fibrillar network that may compromise the ability of cartilage to sustain the high stresses and strains associated with joint loading [234]. These findings are similar to those reported for small animal models of OA including a decreased indentation stiffness of humeral head cartilage in Col2a ${ }^{+/-}$mice [235] and modest decreases in the uniaxial modulus of tibial plateau cartilage in Col11a1 ${ }^{\text {cho/ }+}$ mice [236]. OA chondrons have low pericellular type IX collagen [39], and a loss of type IX collagen with age [29] has been reported which is likely to contribute to the compromised biomechanical integrity of cartilage tissue in OA. This demonstrates the importance of interplay between these ECM molecules in withstanding load and how compromising tissue composition can adversely affect mechanical characteristics perpetuating an OA phenotype (Figure 5).
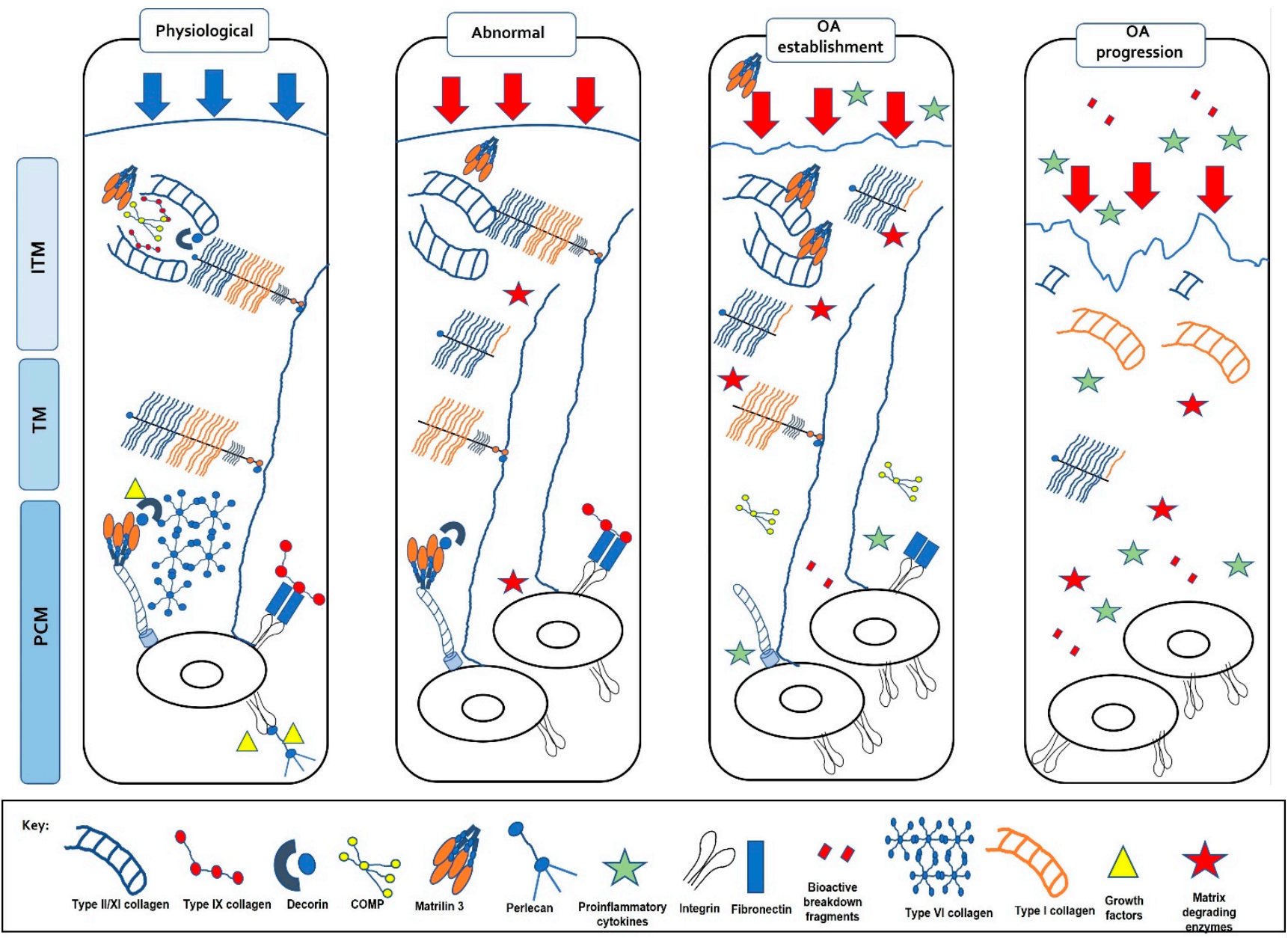

Figure 5. Changes in the extracellular matrix with load. Normal, physiological loads maintain the ECM homeostasis providing the correct biochemical composition which confers its functional properties. Abnormal, pathophysiological loads result in changes in the matrix such as proteoglycan degradation, a loss of the NC4 domain on type IX collagen, reduced type VI collagen and increased type II collagen fibril diameter. This change in matrix compromises the functional properties of the cartilage resulting in OA establishment. Matrilin-3 and COMP increase, pro-inflammatory cytokines and matrix-degrading enzymes are up-regulated, and a switch to type I collagen is observed resulting in OA progression.

With OA, structural and biochemical profiles of the PCM are altered, and degeneration of the PCM is reportedly one of the first events to occur resulting in aberrant chondrocyte mechanotransduction and ultimately cartilage degradation [171,237-239]. Using different micromechanical testing methods such as micropipette aspiration or atomic force 
microscopy (AFM) indentation, studies have revealed that the elastic modulus of the PCM is reduced by $30-50 \%$ in OA cartilage $[237,240,241]$. A net increase in the biosynthesis and deposition of type VI collagen with altered microfibrils [242] results in abnormal swelling and an increase in chondron volume [243]. AFM-based elastic mapping revealed significant alterations in both PCM (30\% decrease) and ECM (45\% decrease) elastic moduli in the medial condyle of OA joints concomitant with an enlarged biomechanical footprint of the PCM [237]. PCM tissue stiffness reduced with changes in spatial patterns of chondrocytes and a reduction in type VI collagen and perlecan correlating with progression of cartilage degeneration in disease [239]. PCM regions rich in perlecan exhibit lower elastic moduli than regions lacking perlecan, and enzymatic removal of HS chains from perlecan with heparinase III increases the PCM elastic moduli both overall and locally in interior regions rich in both perlecan and type VI collagen [91]. Systemic inhibition of ECM remodelling, using a broad-spectrum MMP inhibitor (GM6001), which also reduces aggrecanase activity in the DMM model, preserved the micromodulus of the PCM [171]. Specifically, inhibition of the early injurious load-induced proteolytic degradation of the PCM prevented detrimental alterations to the micromechanical properties of the cartilage matrix, thereby retaining PCM integrity, protecting normal chondrocyte mechanosensing and supporting tissue homeostasis/joint function. Studies in $\mathrm{Dcn}^{-/-}$mice substantiate these findings demonstrating that impairment of PCM properties, due to DCN loss, disrupted chondrocyte mechanotransduction as measured by reduced $\left[\mathrm{Ca}^{2+}\right]_{i}$ signalling in response to osmotic stress, which was more pronounced with age ( $>2$ weeks old) [171]. Interestingly, enzymatic removal of the chondroitin sulphate moieties from aggrecan reduced $\left[\mathrm{Ca}^{2+}\right]_{\mathrm{i}}$ signalling in wild-type mice which was further compounded in the $\mathrm{Dcn}^{-/-}$mice [171]; this demonstrated that the contribution of aggrecan to maintaining a fixed charge in the matrix contributes to the ability of the chondrocyte to sense mechanical loads and elicit early $\left[\mathrm{Ca}^{2+}\right]_{\mathrm{i}}$ signalling responses. Within the ECM, aggrecan and its chondroitin sulphate sGAG moieties provide the net negative charge facilitating sequestration of cations such as $\mathrm{Ca}^{2+}$ for the subsequent activation of ion channels and transmission of mechanical signals. Without these biophysical properties, cartilage chondrocyte mechanotransduction would be severely compromised.

\section{Concluding Remarks}

Articular cartilage responds to mechanical perturbations in the local tissue environment, sensing alterations in the magnitude or type of loading applied, and eliciting cellular behaviours to effect change. In situ, the chondrocytes reside within a dynamic mechanical environment comprising a combination of compression, hydrostatic pressure, shear stress, osmotic stress and tensile strain. Numerous studies have demonstrated the pivotal nature of cell-matrix interactions and the distinct properties conferred by the PCM in regulating the chondrocytes' mechanical environment, influencing cartilage homeostasis and joint health. Specific PCM components, e.g., type VI collagen, perlecan and SLRPs, are instrumental in facilitating the sensing of mechanical signals and orchestrating appropriate mechano-signalling responses. Insight into composition and structure of the PCM, in conjunction with its mechanical properties in cartilage health and pathology, has been instrumental in our understanding of the reciprocity of the PCM/ECM and chondrocyte mechanotransduction. Furthermore, such studies have revealed the complex interplay of loading, inflammation and growth factors on the biochemical and biomechanical hierarchy of articular cartilage. This knowledge can be effectively utilised to guide development of small molecule therapeutics to prevent early remodelling of the PCM, induced by injurious loading, to delay or halt PTOA progression. Furthermore, understanding how physiological loading promotes PCM/ECM synthesis resulting in deposition of a highly organised matrix will aid development of cell constructs containing the hierarchical structure of cartilage for use in tissue-engineering strategies. Although we do not have a complete understanding of chondrocyte behaviour in response to physiological and non-physiological loading, this review demonstrates a clear bidirectional reciprocity between the chondrocyte 
and the PCM/ECM in regulating structural, biomechanical and functional characteristics of articular cartilage and how this can impact tissue health and pathology.

Author Contributions: Conceptualisation-E.J.B.; writing original draft-S.J.G. and E.J.B.; preparation of figures-S.J.G., C.S.B. and E.J.B.; editing draft-S.J.G. and E.J.B.; funding acquisition-E.J.B. All authors have read and agreed to the published version of the manuscript.

Funding: The authors would like to acknowledge the Biomechanics and Bioengineering Research Centre Versus Arthritis (20781) at Cardiff University.

Conflicts of Interest: The authors declare no conflict of interest.

\section{Abbreviations}

ACL anterior cruciate ligament

ADAMTS a disintegrin and metalloproteinase with thrombospondin motifs

AFM atomic force microscopy

BGN biglycan

COMP cartilage oligomeric protein

COX-2 cyclooxygenase-2

CRTC1/2 CREB-regulated transcription coactivator 1

CTGF connective tissue growth factor

CTS cyclic tensile strain

DAMPs damage-associated molecular pattern

DCN decorin

DMM destabilisation of the medial meniscus

ECM extracellular matrix

FGF fibroblast growth factor

FN fibronectin

GAG glycosaminoglycan

HDGF hepatoma-derived growth factor

HSPG2 heparan sulphate proteoglycan 2

IGF1 insulin growth factor 1

Ihh Indian Hedgehog

IL interleukin

LINC linker of nucleoskeleton and cytoskeleton

LRP6 lipoprotein receptor-related protein 6

ITM interterritorial matrix

MAPK mitogen-activated protein kinase

MMP matrix metalloproteinase

NG2 neural/glial antigen 2

OA osteoarthritis

PCM pericellular matrix

PDGF platelet-derived growth factor

PG proteoglycan

$\mathrm{PGE}_{2} \quad$ prostaglandin $\mathrm{E}_{2}$

PRG4 proteoglycan 4

P-SHG polarisation sensitive second harmonic generation

PTOA post-traumatic osteoarthritis

sGAG sulphated glycosaminoglycan

SLRP small leucine-rich proteoglycan

SZ superficial zone

TAL tibial axial loading

TAZ transcriptional co-activator with PDZ-binding motif 


$\begin{array}{ll}\text { TGF } & \text { transforming growth factor } \\ \text { TLRs } & \text { Toll-like receptors } \\ \text { TM } & \text { territorial matrix } \\ \text { TNF } \alpha & \text { tumour necrosis factor alpha } \\ \text { TRPV } & \text { transient receptor potential vanilloid } \\ \text { YAP } & \text { Yes-associated protein }\end{array}$

\section{References}

1. Hunziker, E.B.; Quinn, T.M.; Hauselmann, H.J. Quantitative structural organization of normal adult human articular cartilage. Osteoarthr. Cartil. 2002, 10, 564-572. [CrossRef] [PubMed]

2. Buckwalter, J.A.; Mankin, H.J.; Grodzinsky, A.J. Articular cartilage and osteoarthritis. Instr. Course Lect. 2005, 54, 465-480.

3. Grodzinsky, A.J.; Levenston, M.E.; Jin, M.; Frank, E.H. Cartilage tissue remodeling in response to mechanical forces. Annu. Rev. Biomed. Eng. 2000, 2, 691-713. [CrossRef]

4. Parsons, P.; Gilbert, S.J.; Vaughan-Thomas, A.; Sorrell, D.A.; Notman, R.; Bishop, M.; Hayes, A.J.; Mason, D.J.; Duance, V.C. Type IX collagen interacts with fibronectin providing an important molecular bridge in articular cartilage. J. Biol. Chem. 2011, 286, 34986-34997. [CrossRef] [PubMed]

5. Eyre, D. Collagen of articular cartilage. Arthritis Res. 2002, 4, 30-35. [CrossRef]

6. Heinegard, D. Fell-Muir Lecture: Proteoglycans and more-From molecules to biology. Int. J. Exp. Pathol. 2009, 90, 575-586. [CrossRef] [PubMed]

7. Flowers, S.A.; Zieba, A.; Ornros, J.; Jin, C.; Rolfson, O.; Bjorkman, L.I.; Eisler, T.; Kalamajski, S.; Kamali-Moghaddam, M.; Karlsson, N.G. Lubricin binds cartilage proteins, cartilage oligomeric matrix protein, fibronectin and collagen II at the cartilage surface. Sci. Rep. 2017, 7, 13149. [CrossRef] [PubMed]

8. Flannery, C.R.; Hughes, C.E.; Schumacher, B.L.; Tudor, D.; Aydelotte, M.B.; Kuettner, K.E.; Caterson, B. Articular cartilage superficial zone protein (SZP) is homologous to megakaryocyte stimulating factor precursor and Is a multifunctional proteoglycan with potential growth-promoting, cytoprotective, and lubricating properties in cartilage metabolism. Biochem. Biophys. Res. Commun. 1999, 254, 535-541. [CrossRef]

9. Coles, J.M.; Zhang, L.; Blum, J.J.; Warman, M.L.; Jay, G.D.; Guilak, F.; Zauscher, S. Loss of cartilage structure, stiffness, and frictional properties in mice lacking PRG4. Arthritis Rheum. 2010, 62, 1666-1674. [CrossRef]

10. Jay, G.D.; Torres, J.R.; Rhee, D.K.; Helminen, H.J.; Hytinnen, M.M.; Cha, C.J.; Elsaid, K.; Kim, K.S.; Cui, Y.; Warman, M.L. Association between friction and wear in diarthrodial joints lacking lubricin. Arthritis Rheum. 2007, 56, 3662-3669. [CrossRef]

11. Rhee, D.K.; Marcelino, J.; Baker, M.; Gong, Y.; Smits, P.; Lefebvre, V.; Jay, G.D.; Stewart, M.; Wang, H.; Warman, M.L.; et al. The secreted glycoprotein lubricin protects cartilage surfaces and inhibits synovial cell overgrowth. J. Clin. Investig. 2005, 115, 622-631. [CrossRef] [PubMed]

12. Maenohara, Y.; Chijimatsu, R.; Tachibana, N.; Uehara, K.; Xuan, F.; Mori, D.; Murahashi, Y.; Nakamoto, H.; Oichi, T.; Chang, S.H.; et al. Lubricin Contributes to Homeostasis of Articular Cartilage by Modulating Differentiation of Superficial Zone Cells. J. Bone Miner. Res. 2021, 36, 792-802. [CrossRef] [PubMed]

13. Xuan, F.; Yano, F.; Mori, D.; Chijimatsu, R.; Maenohara, Y.; Nakamoto, H.; Mori, Y.; Makii, Y.; Oichi, T.; Taketo, M.M.; et al. Wnt/beta-catenin signaling contributes to articular cartilage homeostasis through lubricin induction in the superficial zone. Arthritis Res. Ther. 2019, 21, 247. [CrossRef] [PubMed]

14. Gilbert, S.J.; Meakin, L.B.; Bonnet, C.S.; Nowell, M.A.; Ladiges, W.C.; Morton, J.; Duance, V.C.; Mason, D.J. Deletion of P58(IPK), the Cellular Inhibitor of the Protein Kinases PKR and PERK, Causes Bone Changes and Joint Degeneration in Mice. Front. Endocrinol. (Lausanne) 2014, 5, 174. [CrossRef]

15. Zaucke, F.; Grassel, S. Genetic mouse models for the functional analysis of the perifibrillar components collagen IX, COMP and matrilin-3: Implications for growth cartilage differentiation and endochondral ossification. Histol. Histopathol. 2009, 24, 1067-1079. [PubMed]

16. Duance, V.C. Surface of articular cartilage: Immunohistological studies. Cell Biochem. Funct. 1983, 1, 143-144. [CrossRef]

17. Eyre, D.R. The collagens of articular cartilage. Semin. Arthritis Rheum. 1991, 21 (Suppl. 2), 2-11. [CrossRef]

18. Askew, M.J.; Mow, V.C. The Biomechanical Function of the Collagen Fibril Ultrastructure of Articular Cartilage. J. Biomech. Eng. 1978, 100, 105-115. [CrossRef]

19. Pihlajamaa, T.; Lankinen, H.; Ylostalo, J.; Valmu, L.; Jaalinoja, J.; Zaucke, F.; Spitznagel, L.; Gosling, S.; Puustinen, A.; Morgelin, M.; et al. Characterization of recombinant amino-terminal NC4 domain of human collagen IX: Interaction with glycosaminoglycans and cartilage oligomeric matrix protein. J. Biol. Chem. 2004, 279, 24265-24273. [CrossRef] [PubMed]

20. Eyre, D.R. Collagens and cartilage matrix homeostasis. Clin. Orthop. Relat. Res. 2004, 427, S118-S122. [CrossRef]

21. Olsen, B.R. Collagen IX. Int. J. Biochem. Cell Biol. 1997, 29, 555-558. [CrossRef]

22. Wu, J.J.; Woods, P.E.; Eyre, D.R. Identification of cross-linking sites in bovine cartilage type IX collagen reveals an antiparallel type II-type IX molecular relationship and type IX to type IX bonding. J. Biol. Chem. 1992, 267, 23007-23014. [CrossRef]

23. Aigner, T.; Bertling, W.; Stoss, H.; Weseloh, G.; von der Mark, K. Independent expression of fibril-forming collagens I, II, and III in chondrocytes of human osteoarthritic cartilage. J. Clin. Investig. 1993, 91, 829-837. [CrossRef]

24. Wotton, S.F.; Duance, V.C. Type III collagen in normal human articular cartilage. Histochem. J. 1994, 26, 412-416. [CrossRef] 
25. Young, R.D.; Lawrence, P.A.; Duance, V.C.; Aigner, T.; Monaghan, P. Immunolocalization of collagen types II and III in single fibrils of human articular cartilage. J. Histochem. Cytochem. Off. J. Histochem. Soc. 2000, 48, 423-432. [CrossRef]

26. Foldager, C.B.; Toh, W.S.; Gomoll, A.H.; Olsen, B.R.; Spector, M. Distribution of Basement Membrane Molecules, Laminin and Collagen Type IV, in Normal and Degenerated Cartilage Tissues. Cartilage 2014, 5, 123-132. [CrossRef] [PubMed]

27. Kvist, A.J.; Nyström, A.; Hultenby, K.; Sasaki, T.; Talts, J.F.; Aspberg, A. The major basement membrane components localize to the chondrocyte pericellular matrix-a cartilage basement membrane equivalent? Matrix Biol. 2008, 27, 22-33. [CrossRef] [PubMed]

28. Wu, J.J.; Weis, M.A.; Kim, L.S.; Eyre, D.R. Type III collagen, a fibril network modifier in articular cartilage. J. Biol. Chem. 2010, 285, 18537-18544. [CrossRef]

29. Duance, V.C.; Wotton, S.F. Changes in the distribution of mammalian cartilage collagens with age. Biochem. Soc. Trans. 1991, 19, 376S. [CrossRef]

30. Poole, C.A.; Ayad, S.; Schofield, J.R. Chondrons from articular cartilage: I. Immunolocalization of type VI collagen in the pericellular capsule of isolated canine tibial chondrons. J. Cell Sci. 1988, 90 Pt 4, 635-643. [CrossRef] [PubMed]

31. Zelenski, N.A.; Leddy, H.A.; Sanchez-Adams, J.; Zhang, J.; Bonaldo, P.; Liedtke, W.; Guilak, F. Type VI Collagen Regulates Pericellular Matrix Properties, Chondrocyte Swelling, and Mechanotransduction in Mouse Articular Cartilage. Arthritis Rheumatol. 2015, 67, 1286-1294. [CrossRef]

32. Matsumoto, K.; Kamiya, N.; Suwan, K.; Atsumi, F.; Shimizu, K.; Shinomura, T.; Yamada, Y.; Kimata, K.; Watanabe, H. Identification and characterization of versican/PG-M aggregates in cartilage. J. Biol. Chem. 2006, 281, 18257-18263. [CrossRef] [PubMed]

33. Grover, J.; Roughley, P.J. Versican gene expression in human articular cartilage and comparison of mRNA splicing variation with aggrecan. Biochem. J. 1993, 291 Pt 2, 361-367. [CrossRef] [PubMed]

34. Watanabe, H.; Yamada, Y.; Kimata, K. Roles of aggrecan, a large chondroitin sulfate proteoglycan, in cartilage structure and function. J. Biochem. 1998, 124, 687-693. [CrossRef] [PubMed]

35. Lee, V.; Cao, L.; Zhang, Y.; Kiani, C.; Adams, M.E.; Yang, B.B. The roles of matrix molecules in mediating chondrocyte aggregation, attachment, and spreading. J. Cell Biochem. 2000, 79, 322-333. [CrossRef]

36. Kiani, C.; Chen, L.; Wu, Y.J.; Yee, A.J.; Yang, B.B. Structure and function of aggrecan. Cell Res. 2002, 12, 19-32. [CrossRef]

37. Isogai, Z.; Ono, R.N.; Ushiro, S.; Keene, D.R.; Chen, Y.; Mazzieri, R.; Charbonneau, N.L.; Reinhardt, D.P.; Rifkin, D.B.; Sakai, L.Y. Latent transforming growth factor beta-binding protein 1 interacts with fibrillin and is a microfibril-associated protein. J. Biol. Chem. 2003, 278, 2750-2757. [CrossRef] [PubMed]

38. Poole, A.R.; Pidoux, I.; Reiner, A.; Rosenberg, L. An immunoelectron microscope study of the organization of proteoglycan monomer, link protein, and collagen in the matrix of articular cartilage. J. Cell Biol. 1982, 93, 921-937. [CrossRef] [PubMed]

39. Poole, C.A. Articular cartilage chondrons: Form, function and failure. J. Anat. 1997, 191 Pt 1, 1-13. [CrossRef]

40. Quinn, T.M.; Maung, A.A.; Grodzinsky, A.J.; Hunziker, E.B.; Sandy, J.D. Physical and biological regulation of proteoglycan turnover around chondrocytes in cartilage explants. Implications for tissue degradation and repair. Ann. N. Y. Acad. Sci. 1999, 878, 420-441. [CrossRef]

41. Bayliss, M.T.; Howat, S.; Davidson, C.; Dudhia, J. The organization of aggrecan in human articular cartilage. Evidence for age-related changes in the rate of aggregation of newly synthesized molecules. J. Biol. Chem. 2000, 275, 6321-6327. [CrossRef]

42. Quinn, T.M.; Grodzinsky, A.J.; Buschmann, M.D.; Kim, Y.J.; Hunziker, E.B. Mechanical compression alters proteoglycan deposition and matrix deformation around individual cells in cartilage explants. J. Cell Sci. 1998, 111, 573-583. [CrossRef] [PubMed]

43. Klatt, A.R.; Becker, A.K.; Neacsu, C.D.; Paulsson, M.; Wagener, R. The matrilins: Modulators of extracellular matrix assembly. Int. J. Biochem. Cell Biol. 2011, 43, 320-330. [CrossRef] [PubMed]

44. Wiberg, C.; Klatt, A.R.; Wagener, R.; Paulsson, M.; Bateman, J.F.; Heinegard, D.; Morgelin, M. Complexes of matrilin-1 and biglycan or decorin connect collagen VI microfibrils to both collagen II and aggrecan. J. Biol. Chem. 2003, 278, 37698-37704. [CrossRef] [PubMed]

45. Mann, H.H.; Ozbek, S.; Engel, J.; Paulsson, M.; Wagener, R. Interactions between the cartilage oligomeric matrix protein and matrilins. Implications for matrix assembly and the pathogenesis of chondrodysplasias. J. Biol. Chem. 2004, 279, 25294-25298 [CrossRef]

46. Budde, B.; Blumbach, K.; Ylostalo, J.; Zaucke, F.; Ehlen, H.W.; Wagener, R.; Ala-Kokko, L.; Paulsson, M.; Bruckner, P.; Grassel, S. Altered integration of matrilin-3 into cartilage extracellular matrix in the absence of collagen IX. Mol. Cell Biol. 2005, 25, 10465-10478. [CrossRef] [PubMed]

47. Firner, S.; Zaucke, F.; Michael, J.; Dargel, J.; Schiwy-Bochat, K.H.; Heilig, J.; Rothschild, M.A.; Eysel, P.; Brüggemann, G.P.; Niehoff, A. Extracellular Distribution of Collagen II and Perifibrillar Adapter Proteins in Healthy and Osteoarthritic Human Knee Joint Cartilage. J. Histochem. Cytochem. Off. J. Histochem. Soc. 2017, 65, 593-606. [CrossRef] [PubMed]

48. Wagener, R.; Ehlen, H.W.; Ko, Y.P.; Kobbe, B.; Mann, H.H.; Sengle, G.; Paulsson, M. The matrilins-Adaptor proteins in the extracellular matrix. FEBS Lett. 2005, 579, 3323-3329. [CrossRef]

49. Li, P.; Fleischhauer, L.; Nicolae, C.; Prein, C.; Farkas, Z.; Saller, M.M.; Prall, W.C.; Wagener, R.; Heilig, J.; Niehoff, A.; et al. Mice Lacking the Matrilin Family of Extracellular Matrix Proteins Develop Mild Skeletal Abnormalities and Are Susceptible to Age-Associated Osteoarthritis. Int J. Mol. Sci 2020, 21, 666. [CrossRef]

50. Nicolae, C.; Ko, Y.P.; Miosge, N.; Niehoff, A.; Studer, D.; Enggist, L.; Hunziker, E.B.; Paulsson, M.; Wagener, R.; Aszodi, A. Abnormal collagen fibrils in cartilage of matrilin-1/matrilin-3-deficient mice. J. Biol. Chem. 2007, 282, 22163-22175. [CrossRef] 
51. Halasz, K.; Kassner, A.; Morgelin, M.; Heinegard, D. COMP acts as a catalyst in collagen fibrillogenesis. J. Biol. Chem. 2007, 282, 31166-31173. [CrossRef] [PubMed]

52. Holden, P.; Meadows, R.S.; Chapman, K.L.; Grant, M.E.; Kadler, K.E.; Briggs, M.D. Cartilage oligomeric matrix protein interacts with type IX collagen, and disruptions to these interactions identify a pathogenetic mechanism in a bone dysplasia family. J. Biol. Chem. 2001, 276, 6046-6055. [CrossRef] [PubMed]

53. Chen, F.H.; Herndon, M.E.; Patel, N.; Hecht, J.T.; Tuan, R.S.; Lawler, J. Interaction of cartilage oligomeric matrix protein/thrombospondin 5 with aggrecan. J. Biol. Chem. 2007, 282, 24591-24598. [CrossRef] [PubMed]

54. Briggs, M.D.; Chapman, K.L. Pseudoachondroplasia and multiple epiphyseal dysplasia: Mutation review, molecular interactions, and genotype to phenotype correlations. Hum. Mutat. 2002, 19, 465-478. [CrossRef]

55. Blumbach, K.; Bastiaansen-Jenniskens, Y.M.; DeGroot, J.; Paulsson, M.; van Osch, G.J.; Zaucke, F. Combined role of type IX collagen and cartilage oligomeric matrix protein in cartilage matrix assembly: Cartilage oligomeric matrix protein counteracts type IX collagen-induced limitation of cartilage collagen fibril growth in mouse chondrocyte cultures. Arthritis Rheum. 2009, 60, 3676-3685. [CrossRef]

56. Kamper, M.; Hamann, N.; Prein, C.; Clausen-Schaumann, H.; Farkas, Z.; Aszodi, A.; Niehoff, A.; Paulsson, M.; Zaucke, F. Early changes in morphology, bone mineral density and matrix composition of vertebrae lead to disc degeneration in aged collagen IX -/- mice. Matrix Biol. 2016, 49, 132-143. [CrossRef]

57. Guilak, F.; Nims, R.J.; Dicks, A.; Wu, C.L.; Meulenbelt, I. Osteoarthritis as a disease of the cartilage pericellular matrix. Matrix Biol. 2018, 71-72, 40-50. [CrossRef] [PubMed]

58. Haider, M.A.; Schugart, R.C.; Setton, L.A.; Guilak, F. A mechano-chemical model for the passive swelling response of an isolated chondron under osmotic loading. Biomech. Model. Mechanobiol. 2006, 5, 160-171. [CrossRef]

59. Alexopoulos, L.G.; Setton, L.A.; Guilak, F. The biomechanical role of the chondrocyte pericellular matrix in articular cartilage. Acta Biomater. 2005, 1, 317-325. [CrossRef]

60. Khoshgoftar, M.; Torzilli, P.A.; Maher, S.A. Influence of the pericellular and extracellular matrix structural properties on chondrocyte mechanics. J. Orthop. Res. 2018, 36, 721-729. [CrossRef]

61. Knight, M.M.; Lee, D.A.; Bader, D.L. The influence of elaborated pericellular matrix on the deformation of isolated articular chondrocytes cultured in agarose. Biochim. Biophys. Acta 1998, 1405, 67-77. [CrossRef]

62. Guilak, F.; Alexopoulos, L.G.; Upton, M.L.; Youn, I.; Choi, J.B.; Cao, L.; Setton, L.A.; Haider, M.A. The pericellular matrix as a transducer of biomechanical and biochemical signals in articular cartilage. Ann. N. Y. Acad. Sci. 2006, 1068, 498-512. [CrossRef] [PubMed]

63. Wilusz, R.E.; Sanchez-Adams, J.; Guilak, F. The structure and function of the pericellular matrix of articular cartilage. Matrix Biol. 2014, 39, 25-32. [CrossRef]

64. Krishnan, Y.; Grodzinsky, A.J. Cartilage diseases. Matrix Biol. 2018, 71-72, 51-69. [CrossRef] [PubMed]

65. Chery, D.R.; Han, B.; Zhou, Y.; Wang, C.; Adams, S.M.; Chandrasekaran, P.; Kwok, B.; Heo, S.J.; Enomoto-Iwamoto, M.; Lu, X.L.; et al. Decorin regulates cartilage pericellular matrix micromechanobiology. Matrix Biol. 2021, 96, 1-17. [CrossRef]

66. Guilak, F.; Jones, W.R.; Ting-Beall, H.P.; Lee, G.M. The deformation behavior and mechanical properties of chondrocytes in articular cartilage. Osteoarthr. Cartil./OARS Osteoarthr. Res. Soc. 1999, 7, 59-70. [CrossRef]

67. Knight, M.M.; Ghori, S.A.; Lee, D.A.; Bader, D.L. Measurement of the deformation of isolated chondrocytes in agarose subjected to cyclic compression. Med. Eng. Phys. 1998, 20, 684-688. [CrossRef]

68. Knight, M.M.; Ross, J.M.; Sherwin, A.F.; Lee, D.A.; Bader, D.L.; Poole, C.A. Chondrocyte deformation within mechanically and enzymatically extracted chondrons compressed in agarose. Biochim Biophys Acta 2001, 1526, 141-146. [CrossRef]

69. Larson, C.M.; Kelley, S.S.; Blackwood, A.D.; Banes, A.J.; Lee, G.M. Retention of the native chondrocyte pericellular matrix results in significantly improved matrix production. Matrix Biol. 2002, 21, 349-359. [CrossRef]

70. Meredith, J.E., Jr.; Fazeli, B.; Schwartz, M.A. The extracellular matrix as a cell survival factor. Mol. Biol. Cell 1993, 4, $953-961$. [CrossRef]

71. Svoboda, K.K. Chondrocyte-matrix attachment complexes mediate survival and differentiation. Microsc. Res. Tech. 1998, 43, 111-122. [CrossRef]

72. Chen, W.H.; Lai, M.T.; Wu, A.T.; Wu, C.C.; Gelovani, J.G.; Lin, C.T.; Hung, S.C.; Chiu, W.T.; Deng, W.P. In vitro stage-specific chondrogenesis of mesenchymal stem cells committed to chondrocytes. Arthritis Rheum. 2009, 60, 450-459. [CrossRef] [PubMed]

73. Vincent, T.L.; McLean, C.J.; Full, L.E.; Peston, D.; Saklatvala, J. FGF-2 is bound to perlecan in the pericellular matrix of articular cartilage, where it acts as a chondrocyte mechanotransducer. Osteoarthr. Cartil. 2007, 15, 752-763. [CrossRef]

74. Zhang, Z.; Jin, W.; Beckett, J.; Otto, T.; Moed, B. A proteomic approach for identification and localization of the pericellular components of chondrocytes. Histochem. Cell Biol. 2011, 136, 153-162. [CrossRef] [PubMed]

75. Keppie, S.J.; Mansfield, J.C.; Tang, X.; Philp, C.J.; Graham, H.K.; Onnerfjord, P.; Wall, A.; McLean, C.; Winlove, C.P.; Sherratt, M.J.; et al. Matrix-Bound Growth Factors are Released upon Cartilage Compression by an Aggrecan-Dependent Sodium Flux that is Lost in Osteoarthritis. Function 2021, 2, zqab037. [CrossRef]

76. Heinegard, D.; Oldberg, A. Structure and biology of cartilage and bone matrix noncollagenous macromolecules. FASEB J. 1989, 3 , 2042-2051. [CrossRef]

77. Poole, C.A.; Flint, M.H.; Beaumont, B.W. Chondrons in cartilage: Ultrastructural analysis of the pericellular microenvironment in adult human articular cartilages. J. Orthop. Res. Off. Publ. Orthop. Res. Soc. 1987, 5, 509-522. [CrossRef] [PubMed] 
78. Connelly, J.T.; Wilson, C.G.; Levenston, M.E. Characterization of proteoglycan production and processing by chondrocytes and BMSCs in tissue engineered constructs. Osteoarthr. Cartil./OARS Osteoarthr. Res. Soc. 2008, 16, 1092-1100. [CrossRef]

79. Postacchini, F.; Bellocci, M.; Ricciardi-Pollini, P.T.; Modesti, A. An ultrastructural study of recurrent disc herniation: A preliminary report. Spine 1982, 7, 492-497. [CrossRef] [PubMed]

80. Hunziker, E.B.; Michel, M.; Studer, D. Ultrastructure of adult human articular cartilage matrix after cryotechnical processing. Microsc. Res. Tech. 1997, 37, 271-284. [CrossRef]

81. Heinegard, D.; Saxne, T. The role of the cartilage matrix in osteoarthritis. Nat. Rev. Rheumatol. 2011, 7, 50-56. [CrossRef]

82. Poole, C.A.; Ayad, S.; Gilbert, R.T. Chondrons from articular cartilage. V. Immunohistochemical evaluation of type VI collagen organisation in isolated chondrons by light, confocal and electron microscopy. J. Cell Sci. 1992, 103 Pt 4, 1101-1110. [CrossRef]

83. Engvall, E.; Hessle, H.; Klier, G. Molecular assembly, secretion, and matrix deposition of type VI collagen. J. Cell Biol 1986, 102, 703-710. [CrossRef] [PubMed]

84. Doane, K.J.; Howell, S.J.; Birk, D.E. Identification and functional characterization of two type VI collagen receptors, alpha 3 beta 1 integrin and NG2, during avian corneal stromal development. Investig. Ophthalmol. Vis. Sci 1998, 39, $263-275$.

85. Loeser, R.F.; Sadiev, S.; Tan, L.; Goldring, M.B. Integrin expression by primary and immortalized human chondrocytes: Evidence of a differential role for alpha1beta1 and alpha2beta1 integrins in mediating chondrocyte adhesion to types II and VI collagen. Osteoarthr. Cartil./OARS Osteoarthr. Res. Soc. 2000, 8, 96-105. [CrossRef]

86. Luo, Y.; Sinkeviciute, D.; He, Y.; Karsdal, M.; Henrotin, Y.; Mobasheri, A.; Önnerfjord, P.; Bay-Jensen, A. The minor collagens in articular cartilage. Protein Cell 2017, 8, 560-572. [CrossRef] [PubMed]

87. Alexopoulos, L.G.; Youn, I.; Bonaldo, P.; Guilak, F. Developmental and osteoarthritic changes in Col6a1-knockout mice: Biomechanics of type VI collagen in the cartilage pericellular matrix. Arthritis Rheum. 2009, 60, 771-779. [CrossRef]

88. Twomey, J.D.; Thakore, P.I.; Hartman, D.A.; Myers, E.G.; Hsieh, A.H. Roles of type VI collagen and decorin in human mesenchymal stem cell biophysics during chondrogenic differentiation. Eur. Cell Mater. 2014, 27, 237-250. [CrossRef] [PubMed]

89. Guilak, F.; Hayes, A.J.; Melrose, J. Perlecan in Pericellular Mechanosensory Cell-Matrix Communication, Extracellular Matrix Stabilisation and Mechanoregulation of Load-Bearing Connective Tissues. Int. J. Mol. Sci. 2021, 22, 2716. [CrossRef] [PubMed]

90. Melrose, J.; Roughley, P.; Knox, S.; Smith, S.; Lord, M.; Whitelock, J. The structure, location, and function of perlecan, a prominent pericellular proteoglycan of fetal, postnatal, and mature hyaline cartilages. J. Biol. Chem. 2006, 281, 36905-36914. [CrossRef]

91. Wilusz, R.E.; Defrate, L.E.; Guilak, F. A biomechanical role for perlecan in the pericellular matrix of articular cartilage. Matrix Biol. 2012, 31, 320-327. [CrossRef]

92. Vincent, T.; Hermansson, M.; Bolton, M.; Wait, R.; Saklatvala, J. Basic FGF mediates an immediate response of articular cartilage to mechanical injury. Proc. Natl. Acad. Sci. USA 2002, 99, 8259-8264. [CrossRef]

93. Ellman, M.B.; Yan, D.; Ahmadinia, K.; Chen, D.; An, H.S.; Im, H.J. Fibroblast growth factor control of cartilage homeostasis. J. Cell Biochem. 2013, 114, 735-742. [CrossRef]

94. Tang, X.; Muhammad, H.; McLean, C.; Miotla-Zarebska, J.; Fleming, J.; Didangelos, A.; Onnerfjord, P.; Leask, A.; Saklatvala, J.; Vincent, T.L. Connective tissue growth factor contributes to joint homeostasis and osteoarthritis severity by controlling the matrix sequestration and activation of latent TGFbeta. Ann. Rheum. Dis. 2018, 77, 1372-1380. [CrossRef] [PubMed]

95. Arikawa-Hirasawa, E.; Watanabe, H.; Takami, H.; Hassell, J.R.; Yamada, Y. Perlecan is essential for cartilage and cephalic development. Nat. Genet. 1999, 23, 354-358. [CrossRef]

96. Ocken, A.R.; Ku, M.M.; Kinzer-Ursem, T.L.; Calve, S. Perlecan Knockdown Significantly Alters Extracellular Matrix Composition and Organization During Cartilage Development. Mol. Cell Proteom. 2020, 19, 1220-1235. [CrossRef] [PubMed]

97. Xu, X.; Li, Z.; Leng, Y.; Neu, C.P.; Calve, S. Knockdown of the pericellular matrix molecule perlecan lowers in situ cell and matrix stiffness in developing cartilage. Dev. Biol. 2016, 418, 242-247. [CrossRef]

98. Wiberg, C.; Heinegard, D.; Wenglen, C.; Timpl, R.; Morgelin, M. Biglycan organizes collagen VI into hexagonal-like networks resembling tissue structures. J. Biol. Chem. 2002, 277, 49120-49126. [CrossRef]

99. Han, B.; Li, Q.; Wang, C.; Patel, P.; Adams, S.M.; Doyran, B.; Nia, H.T.; Oftadeh, R.; Zhou, S.; Li, C.Y.; et al. Decorin Regulates the Aggrecan Network Integrity and Biomechanical Functions of Cartilage Extracellular Matrix. ACS Nano 2019, 13, 11320-11333. [CrossRef] [PubMed]

100. Ferdous, Z.; Wei, V.M.; Iozzo, R.; Hook, M.; Grande-Allen, K.J. Decorin-transforming growth factor- interaction regulates matrix organization and mechanical characteristics of three-dimensional collagen matrices. J. Biol. Chem. 2007, 282, 35887-35898. [CrossRef]

101. Berendsen, A.D.; Fisher, L.W.; Kilts, T.M.; Owens, R.T.; Robey, P.G.; Gutkind, J.S.; Young, M.F. Modulation of canonical Wnt signaling by the extracellular matrix component biglycan. Proc. Natl. Acad. Sci. USA 2011, 108, 17022-17027. [CrossRef]

102. Dell'accio, F.; De Bari, C.; Eltawil, N.M.; Vanhummelen, P.; Pitzalis, C. Identification of the molecular response of articular cartilage to injury, by microarray screening: Wnt-16 expression and signaling after injury and in osteoarthritis. Arthritis Rheum. 2008, 58, 1410-1421. [CrossRef]

103. Massam-Wu, T.; Chiu, M.; Choudhury, R.; Chaudhry, S.S.; Baldwin, A.K.; McGovern, A.; Baldock, C.; Shuttleworth, C.A.; Kielty, C.M. Assembly of fibrillin microfibrils governs extracellular deposition of latent TGF beta. J. Cell Sci. 2010, 123 Pt 17, 3006-3018. [CrossRef]

104. Thielen, N.G.M.; van der Kraan, P.M.; van Caam, A.P.M. TGFbeta/BMP Signaling Pathway in Cartilage Homeostasis. Cells 2019, 8, 969. [CrossRef] [PubMed] 
105. Neu, C.P.; Khalafi, A.; Komvopoulos, K.; Schmid, T.M.; Reddi, A.H. Mechanotransduction of bovine articular cartilage superficial zone protein by transforming growth factor beta signaling. Arthritis Rheum. 2007, 56, 3706-3714. [CrossRef] [PubMed]

106. Chandrasekhar, S.; Harvey, A.K. Transforming growth factor-beta is a potent inhibitor of IL-1 induced protease activity and cartilage proteoglycan degradation. Biochem. Biophys. Res. Commun. 1988, 157, 1352-1359. [CrossRef]

107. van Beuningen, H.M.; van der Kraan, P.M.; Arntz, O.J.; van den Berg, W.B. In vivo protection against interleukin-1-induced articular cartilage damage by transforming growth factor-beta 1: Age-related differences. Ann. Rheum. Dis. 1994, 53, 593-600. [CrossRef] [PubMed]

108. van Beuningen, H.M.; van der Kraan, P.M.; Arntz, O.J.; van den Berg, W.B. Transforming growth factor-beta 1 stimulates articular chondrocyte proteoglycan synthesis and induces osteophyte formation in the murine knee joint. Lab. Investig. 1994, 71, 279-290.

109. Blaney Davidson, E.N.; Vitters, E.L.; van der Kraan, P.M.; van den Berg, W.B. Expression of transforming growth factor-beta (TGFbeta) and the TGFbeta signalling molecule SMAD-2P in spontaneous and instability-induced osteoarthritis: Role in cartilage degradation, chondrogenesis and osteophyte formation. Ann. Rheum. Dis. 2006, 65, 1414-1421. [CrossRef]

110. Kruegel, J.; Sadowski, B.; Miosge, N. Nidogen-1 and nidogen-2 in healthy human cartilage and in late-stage osteoarthritis cartilage. Arthritis Rheum. 2008, 58, 1422-1432. [CrossRef] [PubMed]

111. Dürr, J.; Lammi, P.; Goodman, S.L.; Aigner, T.; von der Mark, K. Identification and immunolocalization of laminin in cartilage. Exp. Cell Res. 1996, 222, 225-233. [CrossRef]

112. Schminke, B.; Frese, J.; Bode, C.; Goldring, M.B.; Miosge, N. Laminins and Nidogens in the Pericellular Matrix of Chondrocytes: Their Role in Osteoarthritis and Chondrogenic Differentiation. Am. J. Pathol. 2016, 186, 410-418. [CrossRef]

113. Xia, Y.; Darling, E.M.; Herzog, W. Functional properties of chondrocytes and articular cartilage using optical imaging to scanning probe microscopy. J. Orthop. Res. Off. Publ. Orthop. Res. Soc. 2017, 36, 620-631. [CrossRef] [PubMed]

114. Szirmai, J.A. Structure of cartilage. In Aging of Connective and Skeletal Tissue; Engel, A., Larsson, T., Eds.; Nordiska: Stockholm, Sweden, 1969.

115. Mow, V.C.; Guo, X.E. Mechano-electrochemical properties of articular cartilage: Their inhomogeneities and anisotropies. Annu. Rev. Biomed. Eng. 2002, 4, 175-209. [CrossRef]

116. Morrell, K.C.; Hodge, W.A.; Krebs, D.E.; Mann, R.W. Corroboration of in vivo cartilage pressures with implications for synovial joint tribology and osteoarthritis causation. Proc. Natl. Acad. Sci. USA 2005, 102, 14819-14824. [CrossRef] [PubMed]

117. Hodge, W.A.; Fijan, R.S.; Carlson, K.L.; Burgess, R.G.; Harris, W.H.; Mann, R.W. Contact pressures in the human hip joint measured in vivo. Proc. Natl. Acad. Sci. USA 1986, 83, 2879-2883. [CrossRef]

118. Harris, M.D.; Anderson, A.E.; Henak, C.R.; Ellis, B.J.; Peters, C.L.; Weiss, J.A. Finite element prediction of cartilage contact stresses in normal human hips. J. Orthop. Res. 2012, 30, 1133-1139. [CrossRef]

119. Sanchez-Adams, J.; Leddy, H.A.; McNulty, A.L.; O'Conor, C.J.; Guilak, F. The mechanobiology of articular cartilage: Bearing the burden of osteoarthritis. Curr Rheumatol Rep. 2014, 16, 451. [CrossRef] [PubMed]

120. Arokoski, J.P.; Jurvelin, J.S.; Vaatainen, U.; Helminen, H.J. Normal and pathological adaptations of articular cartilage to joint loading. Scand J. Med. Sci Sports 2000, 10, 186-198. [CrossRef]

121. Eckstein, F.; Tieschky, M.; Faber, S.; Englmeier, K.H.; Reiser, M. Functional analysis of articular cartilage deformation, recovery, and fluid flow following dynamic exercise in vivo. Anat. Embryol. (Berl.) 1999, 200, 419-424. [CrossRef]

122. Inamdar, S.R.; Prevost, S.; Terrill, N.J.; Knight, M.M.; Gupta, H.S. Reversible changes in the 3D collagen fibril architecture during cyclic loading of healthy and degraded cartilage. Acta Biomater. 2021, 136, 314-326. [CrossRef] [PubMed]

123. Lee, D.A.; Bader, D.L. Compressive strains at physiological frequencies influence the metabolism of chondrocytes seeded in agarose. J. Orthop. Res. 1997, 15, 181-188. [CrossRef] [PubMed]

124. Buschmann, M.D.; Gluzband, Y.A.; Grodzinsky, A.J.; Hunziker, E.B. Mechanical compression modulates matrix biosynthesis in chondrocyte/agarose culture. J. Cell Sci. 1995, 108 Pt 4, 1497-1508. [CrossRef] [PubMed]

125. Buschmann, M.D.; Kim, Y.J.; Wong, M.; Frank, E.; Hunziker, E.B.; Grodzinsky, A.J. Stimulation of aggrecan synthesis in cartilage explants by cyclic loading is localized to regions of high interstitial fluid flow. Arch. Biochem. Biophys. 1999, 366, 1-7. [CrossRef]

126. Mauck, R.L.; Soltz, M.A.; Wang, C.C.; Wong, D.D.; Chao, P.H.; Valhmu, W.B.; Hung, C.T.; Ateshian, G.A. Functional tissue engineering of articular cartilage through dynamic loading of chondrocyte-seeded agarose gels. J. Biomech. Eng. 2000, 122, 252-260. [CrossRef] [PubMed]

127. Wong, M.; Siegrist, M.; Cao, X. Cyclic compression of articular cartilage explants is associated with progressive consolidation and altered expression pattern of extracellular matrix proteins. Matrix Biol. 1999, 18, 391-399. [CrossRef]

128. Anderson, D.E.; Johnstone, B. Dynamic Mechanical Compression of Chondrocytes for Tissue Engineering: A Critical Review. Front. Bioeng. Biotechnol. 2017, 5, 76. [CrossRef]

129. Chowdhury, T.T.; Bader, D.L.; Shelton, J.C.; Lee, D.A. Temporal regulation of chondrocyte metabolism in agarose constructs subjected to dynamic compression. Arch. Biochem. Biophys. 2003, 417, 105-111. [CrossRef]

130. Kisiday, J.D.; Jin, M.; DiMicco, M.A.; Kurz, B.; Grodzinsky, A.J. Effects of dynamic compressive loading on chondrocyte biosynthesis in self-assembling peptide scaffolds. J. Biomech 2004, 37, 595-604. [CrossRef]

131. Phan, M.N.; Leddy, H.A.; Votta, B.J.; Kumar, S.; Levy, D.S.; Lipshutz, D.B.; Lee, S.H.; Liedtke, W.; Guilak, F. Functional characterization of TRPV4 as an osmotically sensitive ion channel in porcine articular chondrocytes. Arthritis Rheum. 2009, 60, 3028-3037. [CrossRef] [PubMed] 
132. O'Conor, C.J.; Leddy, H.A.; Benefield, H.C.; Liedtke, W.B.; Guilak, F. TRPV4-mediated mechanotransduction regulates the metabolic response of chondrocytes to dynamic loading. Proc. Natl. Acad. Sci. USA 2014, 111, 1316-1321. [CrossRef] [PubMed]

133. Ogawa, H.; Kozhemyakina, E.; Hung, H.H.; Grodzinsky, A.J.; Lassar, A.B. Mechanical motion promotes expression of Prg4 in articular cartilage via multiple CREB-dependent, fluid flow shear stress-induced signaling pathways. Genes Dev. 2014, 28, 127-139. [CrossRef] [PubMed]

134. Guilak, F.; Meyer, B.C.; Ratcliffe, A.; Mow, V.C. The effects of matrix compression on proteoglycan metabolism in articular cartilage explants. Osteoarthr. Cartil. 1994, 2, 91-101. [CrossRef]

135. Sah, R.L.; Doong, J.Y.; Grodzinsky, A.J.; Plaas, A.H.; Sandy, J.D. Effects of compression on the loss of newly synthesized proteoglycans and proteins from cartilage explants. Arch. Biochem. Biophys. 1991, 286, 20-29. [CrossRef]

136. Ragan, P.M.; Badger, A.M.; Cook, M.; Chin, V.I.; Gowen, M.; Grodzinsky, A.J.; Lark, M.W. Down-regulation of chondrocyte aggrecan and type-II collagen gene expression correlates with increases in static compression magnitude and duration. J. Orthop. Res. 1999, 17, 836-842. [CrossRef] [PubMed]

137. Kim, Y.J.; Grodzinsky, A.J.; Plaas, A.H. Compression of cartilage results in differential effects on biosynthetic pathways for aggrecan, link protein, and hyaluronan. Arch. Biochem. Biophys. 1996, 328, 331-340. [CrossRef] [PubMed]

138. Inamdar, S.R.; Knight, D.P.; Terrill, N.J.; Karunaratne, A.; Cacho-Nerin, F.; Knight, M.M.; Gupta, H.S. The Secret Life of Collagen: Temporal Changes in Nanoscale Fibrillar Pre-Strain and Molecular Organization during Physiological Loading of Cartilage. ACS Nano 2017, 11, 9728-9737. [CrossRef] [PubMed]

139. Arokoski, J.P.; Hyttinen, M.M.; Helminen, H.J.; Jurvelin, J.S. Biomechanical and structural characteristics of canine femoral and tibial cartilage. J. Biomed. Mater. Res. 1999, 48, 99-107. [CrossRef]

140. Sharifi, N.; Gharravi, A.M. Shear bioreactors stimulating chondrocyte regeneration, a systematic review. Inflamm. Regen. 2019, 39, 16. [CrossRef]

141. Nugent, G.E.; Aneloski, N.M.; Schmidt, T.A.; Schumacher, B.L.; Voegtline, M.S.; Sah, R.L. Dynamic shear stimulation of bovine cartilage biosynthesis of proteoglycan 4. Arthritis Rheum. 2006, 54, 1888-1896. [CrossRef]

142. Jin, M.; Frank, E.H.; Quinn, T.M.; Hunziker, E.B.; Grodzinsky, A.J. Tissue shear deformation stimulates proteoglycan and protein biosynthesis in bovine cartilage explants. Arch. Biochem. Biophys. 2001, 395, 41-48. [CrossRef] [PubMed]

143. Maroudas, A.I. Balance between swelling pressure and collagen tension in normal and degenerate cartilage. Nature 1976, 260, 808-809. [CrossRef] [PubMed]

144. Guilak, F; Mow, V.C. The mechanical environment of the chondrocyte: A biphasic finite element model of cell-matrix interactions in articular cartilage. J. Biomech. 2000, 33, 1663-1673. [CrossRef]

145. Parkkinen, J.J.; Ikonen, J.; Lammi, M.J.; Laakkonen, J.; Tammi, M.; Helminen, H.J. Effects of cyclic hydrostatic pressure on proteoglycan synthesis in cultured chondrocytes and articular cartilage explants. Arch. Biochem. Biophys. 1993, 300, 458-465. [CrossRef] [PubMed]

146. Hall, A.C.; Urban, J.P.; Gehl, K.A. The effects of hydrostatic pressure on matrix synthesis in articular cartilage. J. Orthop. Res. 1991, 9, 1-10. [CrossRef]

147. Smith, R.L.; Rusk, S.F.; Ellison, B.E.; Wessells, P.; Tsuchiya, K.; Carter, D.R.; Caler, W.E.; Sandell, L.J.; Schurman, D.J. In vitro stimulation of articular chondrocyte mRNA and extracellular matrix synthesis by hydrostatic pressure. J. Orthop Res. 1996, 14, 53-60. [CrossRef]

148. Hodder, E.; Guppy, F.; Covill, D.; Bush, P. The effect of hydrostatic pressure on proteoglycan production in articular cartilage in vitro: A meta-analysis. Osteoarthr. Cartil. 2020, 28, 1007-1019. [CrossRef] [PubMed]

149. Chao, P.H.; West, A.C.; Hung, C.T. Chondrocyte intracellular calcium, cytoskeletal organization, and gene expression responses to dynamic osmotic loading. Am. J. Physiol. Cell Physiol. 2006, 291, C718-C725. [CrossRef]

150. Matthews, B.D.; Thodeti, C.K.; Tytell, J.D.; Mammoto, A.; Overby, D.R.; Ingber, D.E. Ultra-rapid activation of TRPV4 ion channels by mechanical forces applied to cell surface beta1 integrins. Integr. Biol. (Camb.) 2010, 2, 435-442. [CrossRef] [PubMed]

151. Hing, W.A.; Sherwin, A.F.; Poole, C.A. The influence of the pericellular microenvironment on the chondrocyte response to osmotic challenge. Osteoarthr. Cartil. 2002, 10, 297-307. [CrossRef]

152. Nakamoto, H.; Katanosaka, Y.; Chijimatsu, R.; Mori, D.; Xuan, F.; Yano, F.; Omata, Y.; Maenohara, Y.; Murahashi, Y.; Kawaguchi, K.; et al. Involvement of Transient Receptor Potential Vanilloid Channel 2 in the Induction of Lubricin and Suppression of Ectopic Endochondral Ossification in Mouse Articular Cartilage. Arthritis Rheumatol. 2021, 73, 1441-1450. [CrossRef]

153. Guilak, F. Compression-induced changes in the shape and volume of the chondrocyte nucleus. J. Biomech. 1995, $28,1529-1541$. [CrossRef]

154. Zhong, D.; Zhang, M.; Yu, J.; Luo, Z.P. Local Tensile Stress in the Development of Posttraumatic Osteoarthritis. Biomed. Res. Int. 2018, 2018, 4210353. [CrossRef] [PubMed]

155. Thomas, R.S.; Clarke, A.R.; Duance, V.C.; Blain, E.J. Effects of Wnt3A and mechanical load on cartilage chondrocyte homeostasis. Arthritis Res. 2011, 13, R203. [CrossRef] [PubMed]

156. Bleuel, J.; Zaucke, F.; Bruggemann, G.P.; Niehoff, A. Effects of cyclic tensile strain on chondrocyte metabolism: A systematic review. PLoS ONE 2015, 10, e0119816.

157. Matsukawa, M.; Fukuda, K.; Yamasaki, K.; Yoshida, K.; Munakata, H.; Hamanishi, C. Enhancement of nitric oxide and proteoglycan synthesis due to cyclic tensile strain loaded on chondrocytes attached to fibronectin. Inflamm. Res. 2004, 53, 239-244. [CrossRef] [PubMed] 
158. Tanimoto, K.; Kamiya, T.; Tanne, Y.; Kunimatsu, R.; Mitsuyoshi, T.; Tanaka, E.; Tanne, K. Superficial zone protein affects boundary lubrication on the surface of mandibular condylar cartilage. Cell Tissue Res. 2011, 344, 333-340. [CrossRef]

159. Shimizu, A.; Watanabe, S.; Iimoto, S.; Yamamoto, H. Interleukin-4 protects matrix synthesis in chondrocytes under excessive mechanical stress in vitro. Mod. Rheumatol. 2004, 14, 296-300. [CrossRef]

160. Kanbe, K.; Yang, X.; Wei, L.; Sun, C.; Chen, Q. Pericellular matrilins regulate activation of chondrocytes by cyclic load-induced matrix deformation. J. Bone Miner. Res. 2007, 22, 318-328. [CrossRef]

161. Wong, M.; Siegrist, M.; Goodwin, K. Cyclic tensile strain and cyclic hydrostatic pressure differentially regulate expression of hypertrophic markers in primary chondrocytes. Bone 2003, 33, 685-693. [CrossRef]

162. Chen, Y.; Cossman, J.; Jayasuriya, C.T.; Li, X.; Guan, Y.; Fonseca, V.; Yang, K.; Charbonneau, C.; Yu, H.; Kanbe, K.; et al. Deficient Mechanical Activation of Anabolic Transcripts and Post-Traumatic Cartilage Degeneration in Matrilin-1 Knockout Mice. PLoS ONE 2016, 11, e0156676. [CrossRef]

163. Kempson, G.E.; Freeman, M.A.; Swanson, S.A. Tensile properties of articular cartilage. Nature 1968, 220, 1127-1128. [CrossRef]

164. Mansfield, J.C.; Mandalia, V.; Toms, A.; Winlove, C.P.; Brasselet, S. Collagen reorganization in cartilage under strain probed by polarization sensitive second harmonic generation microscopy. J. R. Soc. Interface 2019, 16, 20180611. [CrossRef] [PubMed]

165. Quinn, T.M.; Grodzinsky, A.J.; Hunziker, E.B.; Sandy, J.D. Effects of injurious compression on matrix turnover around individual cells in calf articular cartilage explants. J. Orthop. Res. 1998, 16, 490-499. [CrossRef]

166. Ashwell, M.S.; Gonda, M.G.; Gray, K.; Maltecca, C.; O’Nan, A.T.; Cassady, J.P.; Mente, P.L. Changes in chondrocyte gene expression following in vitro impaction of porcine articular cartilage in an impact injury model. J. Orthop Res. 2013, 31, 385-391. [CrossRef]

167. Gilbert, S.J.; Bonnet, C.S.; Stadnik, P.; Duance, V.C.; Mason, D.J.; Blain, E.J. Inflammatory and degenerative phases resulting from anterior cruciate rupture in a non-invasive murine model of post-traumatic osteoarthritis. J. Orthop. Res. 2018. [CrossRef] [PubMed]

168. Jones, A.R.; Chen, S.; Chai, D.H.; Stevens, A.L.; Gleghorn, J.P.; Bonassar, L.J.; Grodzinsky, A.J.; Flannery, C.R. Modulation of lubricin biosynthesis and tissue surface properties following cartilage mechanical injury. Arthritis Rheum. 2009, 60, 133-142. [CrossRef]

169. Ji, X.; Ito, A.; Nakahata, A.; Nishitani, K.; Kuroki, H.; Aoyama, T. Effects of in vivo cyclic compressive loading on the distribution of local Col2 and superficial lubricin in rat knee cartilage. J. Orthop. Res. Off. Publ. Orthop. Res. Soc. 2021, 39, 543-552. [CrossRef] [PubMed]

170. Stolberg-Stolberg, J.A.; Furman, B.D.; Garrigues, N.W.; Lee, J.; Pisetsky, D.S.; Stearns, N.A.; DeFrate, L.E.; Guilak, F.; Olson, S.A. Effects of cartilage impact with and without fracture on chondrocyte viability and the release of inflammatory markers. J. Orthop. Res. 2013, 31, 1283-1292. [CrossRef]

171. Chery, D.R.; Han, B.; Li, Q.; Zhou, Y.; Heo, S.J.; Kwok, B.; Chandrasekaran, P.; Wang, C.; Qin, L.; Lu, X.L.; et al. Early changes in cartilage pericellular matrix micromechanobiology portend the onset of post-traumatic osteoarthritis. Acta Biomater. 2020, 111, 267-278. [CrossRef]

172. Li, Q.; Han, B.; Wang, C.; Tong, W.; Wei, Y.; Tseng, W.J.; Han, L.H.; Liu, X.S.; Enomoto-Iwamoto, M.; Mauck, R.L.; et al. Mediation of Cartilage Matrix Degeneration and Fibrillation by Decorin in Post-traumatic Osteoarthritis. Arthritis Rheumatol. 2020, 72, 1266-1277. [CrossRef]

173. Han, B.; Li, Q.; Wang, C.; Chandrasekaran, P.; Zhou, Y.; Qin, L.; Liu, X.S.; Enomoto-Iwamoto, M.; Kong, D.; Iozzo, R.V.; et al. Differentiated activities of decorin and biglycan in the progression of post-traumatic osteoarthritis. Osteoarthr. Cartil. 2021, 29, 1181-1192. [CrossRef] [PubMed]

174. Gronau, T.; Kruger, K.; Prein, C.; Aszodi, A.; Gronau, I.; Iozzo, R.V.; Mooren, F.C.; Clausen-Schaumann, H.; Bertrand, J.; Pap, T.; et al. Forced exercise-induced osteoarthritis is attenuated in mice lacking the small leucine-rich proteoglycan decorin. Ann. Rheum. Dis. 2017, 76, 442-449. [CrossRef] [PubMed]

175. Wang, W.; Rigueur, D.; Lyons, K.M. TGFbeta signaling in cartilage development and maintenance. Birth Defects Res. C Embryo Today 2014, 102, 37-51. [CrossRef]

176. Okamura, N.; Hasegawa, M.; Nakoshi, Y.; Iino, T.; Sudo, A.; Imanaka-Yoshida, K.; Yoshida, T.; Uchida, A. Deficiency of tenascin-C delays articular cartilage repair in mice. Osteoarthr. Cartil. 2010, 18, 839-848. [CrossRef]

177. Madej, W.; van Caam, A.; Blaney Davidson, E.N.; van der Kraan, P.M.; Buma, P. Physiological and excessive mechanical compression of articular cartilage activates Smad2/3P signaling. Osteoarthr. Cartil. 2014, 22, 1018-1025. [CrossRef] [PubMed]

178. Madej, W.; van Caam, A.; Blaney Davidson, E.; Buma, P.; van der Kraan, P.M. Unloading results in rapid loss of TGFbeta signaling in articular cartilage: Role of loading-induced TGFbeta signaling in maintenance of articular chondrocyte phenotype? Osteoarthr. Cartil. 2016, 24, 1807-1815. [CrossRef]

179. Gilbert, S.J.; Blain, E.J. Cartilage mechanobiology: How chondrocytes respond to mechanical load. In Mechanobiology in Health and Disease; Verbruggen, S.W., Ed.; Elsevier: London, UK, 2018; pp. 99-126.

180. Lee, W.; Guilak, F.; Liedtke, W. Role of Piezo Channels in Joint Health and Injury. Curr Top. Membr 2017, 79, 263-273. [PubMed]

181. Lee, W.; Leddy, H.A.; Chen, Y.; Lee, S.H.; Zelenski, N.A.; McNulty, A.L.; Wu, J.; Beicker, K.N.; Coles, J.; Zauscher, S.; et al. Synergy between Piezo1 and Piezo2 channels confers high-strain mechanosensitivity to articular cartilage. Proc. Natl. Acad. Sci. USA 2014, 111, E5114-E5122. [CrossRef] 
182. Du, G.; Li, L.; Zhang, X.; Liu, J.; Hao, J.; Zhu, J.; Wu, H.; Chen, W.; Zhang, Q. Roles of TRPV4 and piezo channels in stretch-evoked $\mathrm{Ca}(2+)$ response in chondrocytes. Exp. Biol. Med. (Maywood) 2020, 245, 180-189. [CrossRef]

183. Zhao, Z.; Li, Y.; Wang, M.; Zhao, S.; Zhao, Z.; Fang, J. Mechanotransduction pathways in the regulation of cartilage chondrocyte homoeostasis. J. Cell Mol. Med. 2020, 24, 5408-5419. [CrossRef]

184. Jiang, W.; Liu, H.; Wan, R.; Wu, Y.; Shi, Z.; Huang, W. Mechanisms linking mitochondrial mechanotransduction and chondrocyte biology in the pathogenesis of osteoarthritis. Ageing Res. Rev. 2021, 67, 101315. [CrossRef]

185. Blain, E.J. Involvement of the cytoskeletal elements in articular cartilage mechanotransduction. In Mechanosensitivity and Mechanotransduction; Kamkin, A., Kiseleva, I., Eds.; Springer: Berlin/Heidelberg, Germany; Volume 4, pp. 77-108.

186. Campbell, J.J.; Blain, E.J.; Chowdhury, T.T.; Knight, M.M. Loading alters actin dynamics and up-regulates cofilin gene expression in chondrocytes. Biochem. Biophys. Res. Commun. 2007, 361, 329-334. [CrossRef] [PubMed]

187. Xu, R.; Boudreau, A.; Bissell, M.J. Tissue architecture and function: Dynamic reciprocity via extra- and intra-cellular matrices. Cancer Metastasis Rev. 2009, 28, 167-176. [CrossRef]

188. Haudenschild, D.R.; D'Lima, D.D.; Lotz, M.K. Dynamic compression of chondrocytes induces a Rho kinase-dependent reorganization of the actin cytoskeleton. Biorheology 2008, 45, 219-228. [CrossRef]

189. Yang, K.; Wu, Y.; Cheng, P.; Zhang, J.; Yang, C.; Pi, B.; Ye, Y.; You, H.; Chen, A.; Xu, T.; et al. YAP and ERK mediated mechanical strain-induced cell cycle progression through RhoA and cytoskeletal dynamics in rat growth plate chondrocytes. J. Orthop. Res. 2016, 34, 1121-1129. [CrossRef] [PubMed]

190. Fitzgerald, J.B.; Jin, M.; Chai, D.H.; Siparsky, P.; Fanning, P.; Grodzinsky, A.J. Shear- and compression-induced chondrocyte transcription requires MAPK activation in cartilage explants. J. Biol. Chem. 2008, 283, 6735-6743. [CrossRef]

191. Bougault, C.; Aubert-Foucher, E.; Paumier, A.; Perrier-Groult, E.; Huot, L.; Hot, D.; Duterque-Coquillaud, M.; Mallein-Gerin, F. Dynamic compression of chondrocyte-agarose constructs reveals new candidate mechanosensitive genes. PLoS ONE 2012, 7 , e36964.

192. Fanning, P.J.; Emkey, G.; Smith, R.J.; Grodzinsky, A.J.; Szasz, N.; Trippel, S.B. Mechanical regulation of mitogen-activated protein kinase signaling in articular cartilage. J. Biol. Chem. 2003, 278, 50940-50948. [CrossRef]

193. D'Andrea, P.; Calabrese, A.; Capozzi, I.; Grandolfo, M.; Tonon, R.; Vittur, F. Intercellular Ca2+ waves in mechanically stimulated articular chondrocytes. Biorheology 2000, 37, 75-83. [CrossRef]

194. Han, S.K.; Wouters, W.; Clark, A.; Herzog, W. Mechanically induced calcium signaling in chondrocytes in situ. J. Orthop. Res. 2012, 30, 475-481. [CrossRef]

195. Pingguan-Murphy, B.; El-Azzeh, M.; Bader, D.L.; Knight, M.M. Cyclic compression of chondrocytes modulates a purinergic calcium signalling pathway in a strain rate- and frequency-dependent manner. J. Cell Physiol. 2006, 209, 389-397. [CrossRef]

196. Dupont, S. Role of YAP/TAZ in cell-matrix adhesion-mediated signalling and mechanotransduction. Exp. Cell Res. 2016, 343, 42-53. [CrossRef] [PubMed]

197. Crisp, M.; Liu, Q.; Roux, K.; Rattner, J.B.; Shanahan, C.; Burke, B.; Stahl, P.D.; Hodzic, D. Coupling of the nucleus and cytoplasm: Role of the LINC complex. J. Cell Biol. 2006, 172, 41-53. [CrossRef] [PubMed]

198. Lityagina, O.; Dobreva, G. The LINC Between Mechanical Forces and Chromatin. Front. Physiol. 2021, 12, 710809. [CrossRef]

199. Swift, J.; Discher, D.E. The nuclear lamina is mechano-responsive to ECM elasticity in mature tissue. J. Cell Sci. 2014, 127 Pt 14, 3005-3015. [CrossRef] [PubMed]

200. Gesson, K.; Rescheneder, P.; Skoruppa, M.P.; von Haeseler, A.; Dechat, T.; Foisner, R. A-type lamins bind both hetero- and euchromatin, the latter being regulated by lamina-associated polypeptide 2 alpha. Genome Res. 2016, 26, 462-473. [CrossRef]

201. Amar, K.; Wei, F.; Chen, J.; Wang, N. Effects of forces on chromatin. APL Bioeng. 2021, 5, 041503. [CrossRef]

202. Sebastian, A.; Chang, J.C.; Mendez, M.E.; Murugesh, D.K.; Hatsell, S.; Economides, A.N.; Christiansen, B.A.; Loots, G.G. Comparative Transcriptomics Identifies Novel Genes and Pathways Involved in Post-Traumatic Osteoarthritis Development and Progression. Int. J. Mol. Sci. 2018, 19, 2657. [CrossRef]

203. Sui, Y.; Lee, J.H.; DiMicco, M.A.; Vanderploeg, E.J.; Blake, S.M.; Hung, H.H.; Plaas, A.H.; James, I.E.; Song, X.Y.; Lark, M.W.; et al. Mechanical injury potentiates proteoglycan catabolism induced by interleukin- 6 with soluble interleukin-6 receptor and tumor necrosis factor alpha in immature bovine and adult human articular cartilage. Arthritis Rheum. 2009, 60, 2985-2996. [CrossRef]

204. Ding, L.; Guo, D.; Homandberg, G.A.; Buckwalter, J.A.; Martin, J.A. A single blunt impact on cartilage promotes fibronectin fragmentation and upregulates cartilage degrading stromelysin-1/matrix metalloproteinase- 3 in a bovine ex vivo model. J. Orthop. Res. 2014, 32, 811-818. [CrossRef] [PubMed]

205. Blain, E.J. Mechanical regulation of matrix metalloproteinases. Front. Biosci. 2007, 12, 507-527. [CrossRef] [PubMed]

206. Sun, H.B.; Zhao, L.; Tanaka, S.; Yokota, H. Moderate joint loading reduces degenerative actions of matrix metalloproteinases in the articular cartilage of mouse ulnae. Connect. Tissue Res. 2012, 53, 180-186. [CrossRef] [PubMed]

207. Pap, G.; Eberhardt, R.; Sturmer, I.; Machner, A.; Schwarzberg, H.; Roessner, A.; Neumann, W. Development of osteoarthritis in the knee joints of Wistar rats after strenuous running exercise in a running wheel by intracranial self-stimulation. Pathol. Res. Pract. 1998, 194, 41-47. [CrossRef]

208. Yokota, H.; Goldring, M.B.; Sun, H.B. CITED2-mediated regulation of MMP-1 and MMP-13 in human chondrocytes under flow shear. J. Biol. Chem. 2003, 278, 47275-47280. [CrossRef]

209. Sokolove, J.; Lepus, C.M. Role of inflammation in the pathogenesis of osteoarthritis: Latest findings and interpretations. Adv. Musculoskelet. Dis. 2013, 5, 77-94. [CrossRef] 
210. Lambert, C.; Zappia, J.; Sanchez, C.; Florin, A.; Dubuc, J.E.; Henrotin, Y. The Damage-Associated Molecular Patterns (DAMPs) as Potential Targets to Treat Osteoarthritis: Perspectives From a Review of the Literature. Front. Med. (Lausanne) 2020, 7, 607186. [CrossRef]

211. Fichter, M.; Korner, U.; Schomburg, J.; Jennings, L.; Cole, A.A.; Mollenhauer, J. Collagen degradation products modulate matrix metalloproteinase expression in cultured articular chondrocytes. J. Orthop. Res. Off. Publ. Orthop. Res. Soc. 2006, 24, 63-70. [CrossRef]

212. Heathfield, T.F.; Onnerfjord, P.; Dahlberg, L.; Heinegard, D. Cleavage of fibromodulin in cartilage explants involves removal of the $\mathrm{N}$-terminal tyrosine sulfate-rich region by proteolysis at a site that is sensitive to matrix metalloproteinase-13. J. Biol. Chem. 2004, 279, 6286-6295. [CrossRef]

213. Knudson, W.; Casey, B.; Nishida, Y.; Eger, W.; Kuettner, K.E.; Knudson, C.B. Hyaluronan oligosaccharides perturb cartilage matrix homeostasis and induce chondrocytic chondrolysis. Arthritis Rheum. 2000, 43, 1165-1174. [CrossRef]

214. Sofat, N.; Robertson, S.D.; Hermansson, M.; Jones, J.; Mitchell, P.; Wait, R. Tenascin-C fragments are endogenous inducers of cartilage matrix degradation. Rheumatol. Int. 2012, 32, 2809-2817. [CrossRef] [PubMed]

215. Lees, S.; Golub, S.B.; Last, K.; Zeng, W.; Jackson, D.C.; Sutton, P.; Fosang, A.J. Bioactivity in an Aggrecan 32-mer Fragment Is Mediated via Toll-like Receptor 2. Arthritis Rheumatol. 2015, 67, 1240-1249. [CrossRef] [PubMed]

216. Wood, S.T.; Long, D.L.; Reisz, J.A.; Yammani, R.R.; Burke, E.A.; Klomsiri, C.; Poole, L.B.; Furdui, C.M.; Loeser, R.F. CysteineMediated Redox Regulation of Cell Signaling in Chondrocytes Stimulated With Fibronectin Fragments. Arthritis Rheumatol. 2016, 68, 117-126. [CrossRef] [PubMed]

217. Rosenberg, J.H.; Rai, V.; Dilisio, M.F.; Sekundiak, T.D.; Agrawal, D.K. Increased expression of damage-associated molecular patterns (DAMPs) in osteoarthritis of human knee joint compared to hip joint. Mol. Cell. Biochem. 2017, 436, 59-69. [CrossRef]

218. Xie, D.L.; Meyers, R.; Homandberg, G.A. Fibronectin fragments in osteoarthritic synovial fluid. J. Rheumatol. 1992, 19, 1448-1452.

219. Dunn, S.L.; Soul, J.; Anand, S.; Schwartz, J.M.; Boot-Handford, R.P.; Hardingham, T.E. Gene expression changes in damaged osteoarthritic cartilage identify a signature of non-chondrogenic and mechanical responses. Osteoarthr. Cartil./OARS Osteoarthr. Res. Soc. 2016, 24, 1431-1440. [CrossRef]

220. Barreto, G.; Soininen, A.; Ylinen, P.; Sandelin, J.; Konttinen, Y.T.; Nordstrom, D.C.; Eklund, K.K. Soluble biglycan: A potential mediator of cartilage degradation in osteoarthritis. Arthritis Res. 2015, 17, 379. [CrossRef] [PubMed]

221. Melrose, J.; Fuller, E.S.; Roughley, P.J.; Smith, M.M.; Kerr, B.; Hughes, C.E.; Caterson, B.; Little, C.B. Fragmentation of decorin, biglycan, lumican and keratocan is elevated in degenerate human meniscus, knee and hip articular cartilages compared with age-matched macroscopically normal and control tissues. Arthritis Res. 2008, 10, R79. [CrossRef] [PubMed]

222. Miller, R.E.; Ishihara, S.; Tran, P.B.; Golub, S.B.; Last, K.; Miller, R.J.; Fosang, A.J.; Malfait, A.M. An aggrecan fragment drives osteoarthritis pain through Toll-like receptor 2. JCI Insight 2018, 3, e95704. [CrossRef]

223. Patwari, P.; Cook, M.N.; DiMicco, M.A.; Blake, S.M.; James, I.E.; Kumar, S.; Cole, A.A.; Lark, M.W.; Grodzinsky, A.J. Proteoglycan degradation after injurious compression of bovine and human articular cartilage in vitro: Interaction with exogenous cytokines. Arthritis Rheum. 2003, 48, 1292-1301. [CrossRef] [PubMed]

224. Murata, M.; Bonassar, L.J.; Wright, M.; Mankin, H.J.; Towle, C.A. A role for the interleukin-1 receptor in the pathway linking static mechanical compression to decreased proteoglycan synthesis in surface articular cartilage. Arch. Biochem. Biophys. 2003, 413, 229-235. [CrossRef]

225. Furman, B.D.; Mangiapani, D.S.; Zeitler, E.; Bailey, K.N.; Horne, P.H.; Huebner, J.L.; Kraus, V.B.; Guilak, F.; Olson, S.A. Targeting pro-inflammatory cytokines following joint injury: Acute intra-articular inhibition of interleukin-1 following knee injury prevents post-traumatic arthritis. Arthritis Res. 2014, 16, R134. [CrossRef] [PubMed]

226. Takeda, Y.; Niki, Y.; Fukuhara, Y.; Fukuda, Y.; Udagawa, K.; Shimoda, M.; Kikuchi, T.; Kobayashi, S.; Harato, K.; Miyamoto, T.; et al. Compressive mechanical stress enhances susceptibility to interleukin-1 by increasing interleukin-1 receptor expression in 3D-cultured ATDC5 cells. BMC Musculoskelet. Disord. 2021, 22, 238. [CrossRef] [PubMed]

227. Li, Y.; Frank, E.H.; Wang, Y.; Chubinskaya, S.; Huang, H.H.; Grodzinsky, A.J. Moderate dynamic compression inhibits procatabolic response of cartilage to mechanical injury, tumor necrosis factor-alpha and interleukin-6, but accentuates degradation above a strain threshold. Osteoarthr. Cartil. 2013, 21, 1933-1941. [CrossRef]

228. Hazbun, L.; Martinez, J.A.; Best, T.M.; Kaplan, L.; Huang, C.Y. Anti-inflammatory effects of tibial axial loading on knee articular cartilage post traumatic injury. J. Biomech. 2021, 128, 110736. [CrossRef]

229. Akizuki, S.; Mow, V.C.; Muller, F.; Pita, J.C.; Howell, D.S.; Manicourt, D.H. Tensile properties of human knee joint cartilage: I. Influence of ionic conditions, weight bearing, and fibrillation on the tensile modulus. J. Orthop. Res. Off. Publ. Orthop. Res. Soc. 1986, 4, 379-392. [CrossRef]

230. LeRoux, M.A.; Arokoski, J.; Vail, T.P.; Guilak, F.; Hyttinen, M.M.; Kiviranta, I.; Setton, L.A. Simultaneous changes in the mechanical properties, quantitative collagen organization, and proteoglycan concentration of articular cartilage following canine meniscectomy. J. Orthop. Res. Off. Publ. Orthop. Res. Soc. 2000, 18, 383-392. [CrossRef]

231. Pastrama, M.I.; Ortiz, A.C.; Zevenbergen, L.; Famaey, N.; Gsell, W.; Neu, C.P.; Himmelreich, U.; Jonkers, I. Combined enzymatic degradation of proteoglycans and collagen significantly alters intratissue strains in articular cartilage during cyclic compression. J. Mech. Behav. Biomed. Mater. 2019, 98, 383-394. [CrossRef] 
232. Poole, A.R.; Kobayashi, M.; Yasuda, T.; Laverty, S.; Mwale, F.; Kojima, T.; Sakai, T.; Wahl, C.; El-Maadawy, S.; Webb, G.; et al. Type II collagen degradation and its regulation in articular cartilage in osteoarthritis. Ann. Rheum. Dis 2002, 61 (Suppl. 2), ii78-ii81. [CrossRef]

233. Mow, V.C.; Setton, L.A.; Guilak, F.; Ratcliffe, A. Mechanical factors in articular cartilage and their role in osteoarthritis. In Osteoarthritic Disorders; Goldberg, V.M., Ed.; American Academy of Orthopaedic Surgeons: Rosemont, IL, USA, 1995; pp. 142-172.

234. Hu, K.; Xu, L.; Cao, L.; Flahiff, C.M.; Brussiau, J.; Ho, K.; Setton, L.A.; Youn, I.; Guilak, F.; Olsen, B.R.; et al. Pathogenesis of osteoarthritis-like changes in the joints of mice deficient in type IX collagen. Arthritis Rheum. 2006, 54, 2891-2900. [CrossRef]

235. Hyttinen, M.M.; Toyras, J.; Lapvetelainen, T.; Lindblom, J.; Prockop, D.J.; Li, S.W.; Arita, M.; Jurvelin, J.S.; Helminen, H.J. Inactivation of one allele of the type II collagen gene alters the collagen network in murine articular cartilage and makes cartilage softer. Ann. Rheum. Dis. 2001, 60, 262-268. [CrossRef]

236. Xu, L.; Flahiff, C.M.; Waldman, B.A.; Wu, D.; Olsen, B.R.; Setton, L.A.; Li, Y. Osteoarthritis-like changes and decreased mechanical function of articular cartilage in the joints of mice with the chondrodysplasia gene (cho). Arthritis Rheum. 2003, 48, $2509-2518$. [CrossRef]

237. Wilusz, R.E.; Zauscher, S.; Guilak, F. Micromechanical mapping of early osteoarthritic changes in the pericellular matrix of human articular cartilage. Osteoarthr. Cartil./OARS Osteoarthr. Res. Soc. 2013, 21, 1895-1903. [CrossRef] [PubMed]

238. Danalache, M.; Jacobi, L.F.; Schwitalle, M.; Hofmann, U.K. Assessment of biomechanical properties of the extracellular and pericellular matrix and their interconnection throughout the course of osteoarthritis. J. Biomech. 2019, 97, 109409. [CrossRef]

239. Danalache, M.; Kleinert, R.; Schneider, J.; Erler, A.L.; Schwitalle, M.; Riester, R.; Traub, F.; Hofmann, U.K. Changes in stiffness and biochemical composition of the pericellular matrix as a function of spatial chondrocyte organisation in osteoarthritic cartilage. Osteoarthr. Cartil./OARS Osteoarthr. Res. Soc. 2019, 27, 823-832. [CrossRef]

240. Alexopoulos, L.G.; Haider, M.A.; Vail, T.P.; Guilak, F. Alterations in the mechanical properties of the human chondrocyte pericellular matrix with osteoarthritis. J. Biomech. Eng. 2003, 125, 323-333. [CrossRef] [PubMed]

241. Alexopoulos, L.G.; Williams, G.M.; Upton, M.L.; Setton, L.A.; Guilak, F. Osteoarthritic changes in the biphasic mechanical properties of the chondrocyte pericellular matrix in articular cartilage. J. Biomech. 2005, 38, 509-517. [CrossRef]

242. Soder, S.; Hambach, L.; Lissner, R.; Kirchner, T.; Aigner, T. Ultrastructural localization of type VI collagen in normal adult and osteoarthritic human articular cartilage. Osteoarthr. Cartil./OARS Osteoarthr. Res. Soc. 2002, 10, 464-470. [CrossRef]

243. Lee, G.M.; Paul, T.A.; Slabaugh, M.; Kelley, S.S. The incidence of enlarged chondrons in normal and osteoarthritic human cartilage and their relative matrix density. Osteoarthr. Cartil./OARS Osteoarthr. Res. Soc. 2000, 8, 44-52. [CrossRef] [PubMed] 